\title{
EN TORNO A LA TEORÍA SAUSSUREANA DE LA MOTIVACIÓN LINGÜÍSTICA ${ }^{1}$
}

\author{
María Tadea Díaz Hormigo \\ Universidad de Cádiz \\ tadea.diaz@uca.es
}

\begin{abstract}
Resumen
Entre las teorías, conceptos y distinciones que, por aparecer expuestos por primera vez en el Cours de linguistique générale, podría considerarse que constituyen aportaciones originales de Saussure pero que, sin embargo, no han sido suficientemente declarados y reconocidos como propios del maestro de Ginebra, se encuentran las precisiones establecidas por éste respecto a la denominada actualmente teoría de la motivación lingüística, tema en el que centramos nuestro artículo, que tiene como objetivo, más que discernir las conexiones que su concepción manifiesta con las reflexiones en torno al lenguaje anteriores a él, fundamentalmente, determinar su influencia en la lingüística posterior. La conclusión a la que se llega es que la teoría de la motivación lingüística de Saussure es retomada por otros autores, que, sin embargo, no reconocen su deuda con él y, además, proponen una ampliación que desvirtúa y contraviene su concepción.
\end{abstract}

PALABRAS CLAVE: Saussure, motivación lingüística, signo lingüístico, arbitrariedad

\begin{abstract}
Among the theories, concepts and distinctions, which, having been mentioned for the very first time in the Cours de linguistique générale, could be considered as original Saussurean contributions, some points established by this scholar concerning the current theory of motivation in language may be found. Such contributions, however, have not been sufficiently attributed or indebted to the Professor from Geneva. This fact is focused on throughout this paper whose main objective is to analyse the influence of the Saussurean concept on the theory of motivation in language in subsequent linguistic theories rather than to distinguish the connections that his conception maintains with other reflections on language prior to his. We conclude that Saussure's theory of motivation in language is taken up by these authors who, nevertheless, do not admit their debt to him and, moreover, they advocate a widening of the scope of the proposal which distorts and contravenes his conceptions.
\end{abstract}

KEY WORDS: Saussure, motivation in language, linguistic sign, arbitrariness

1 El presente estudio se inserta parcialmente en las líneas de investigación que estamos desarrollando en el marco de los proyectos «Fraseografía teórica y práctica. Bases para la elaboración de un diccionario de locuciones» (HUM2007-60649/FILO) del Plan Nacional de I+D+i del Ministerio de Educación y Ciencia, financiado por el MEC y por los Fondos Feder en su convocatoria del 2006, y «Estudio de la comunicación social y estrategias lingüísticas en las interacciones médico-paciente, Administración-ciudadano y empresa-cliente» (HUM 1202), financiado, durante el período 2006-2009, por la Dirección General de Investigación, Tecnología y Empresa de la Junta de Andalucía en su convocatoria de 2005 para la concesión de incentivos a proyectos de investigación de excelencia en equipos de investigación. En concreto, el artículo que presentamos se adscribe a la línea que tiene como objeto analizar la motivación de las formaciones derivadas y compuestas y de las unidades fraseológicas, pues entendemos que, para llevar a cabo tal labor, es tarea previa la revisión de la teoría de la motivación lingüística en general y de los distintos tipos de motivación en particular. Otros acercamientos anteriores de miembros de estos proyectos a este tema de indagación son los que figuran, fundamentalmente, en Díaz Hormigo (2006a; 2006b), Penadés Martínez (2006) y Penadés Martínez y Díaz Hormigo (2008), aunque véase también la n. 28 de este trabajo. 
1. Es bien sabido que ciertas nociones, teorías y distinciones que, por figurar explícitamente formuladas y fundamentadas en el Cours de linguistique générale (CLG), suelen atribuirse casi siempre a F. de Saussure no son originales de éste sino que, por el contrario, son propias de otros pensadores y estudiosos que ya las habían establecido con anterioridad. Pero, junto al empeño -en ocasiones, desde nuestro punto de vista, excesivo- que han puesto algunos investigadores tanto en determinar los autores que han ejercido alguna influencia, aunque fuera mínima, sobre Saussure, señalar las coincidencias y entablar los lazos históricos como en precisar las fuentes, los precursores y los antecedentes de prácticamente todas las ideas, formulaciones e intuiciones saussureanas, observamos también que determinadas teorías y conceptos expuestos por el maestro de Ginebra, y que puede considerarse que constituyen, por tanto, algunas de las auténticas aportaciones de éste a la lingüística posterior, no han sido suficientemente declarados y reconocidos como propios del lingüista suizo, pasando en la mayoría de las ocasiones inadvertido el hecho de que su origen se encuentra precisamente en Saussure. Un ejemplo de esto último lo encontramos en algunas precisiones establecidas por el considerado precursor del estructuralismo lingüístico respecto a la denominada actualmente teoría de la motivación lingüística, tema este en el que centraremos nuestro artículo, que tiene como objetivo último discernir las conexiones que manifiesta la formulación de la mencionada teoría por parte de Saussure con las reflexiones en torno al lenguaje anteriores a él y las relaciones que presenta con la lingüística posterior, basándonos para ello, fundamentalmente, en el manejo de dos de los tres criterios que, según Koerner (1989[1987]), permiten la aplicación del término influencia, concretamente, el de la evidencia establecida por los paralelismos textuales entre una teoría o un concepto particular y sus supuestas fuentes y el de las referencias directas de un autor a la obra de otros.

No obstante, puesto que la teoría saussureana de la motivación lingüística -o de limitación de lo arbitrario- resulta de la exposición, por parte del mismo Saussure, del principio de la arbitrariedad del signo lingüístico, en el apartado 2. de este artículo analizaremos, remitiendo a los antecedentes de la misma, la concepción saussureana de lo arbitrario, mientras que en el apartado 3. revisaremos los argumentos esgrimidos por Saussure para defender el carácter arbitrario del signo lingüístico y determinaremos qué pruebas de las citadas por el lingüista de Ginebra se encontraban ya en la tradición y cuáles han sido retomadas y citadas por autores posteriores al autor suizo, para, en el apartado 4., proceder del mismo modo con las razones apuntadas por él mismo para defender el carácter arbitrario de aquellas unidades lingüísticas (onomatopeyas y exclamaciones) que podrían ser consideradas excepciones a dicho principio, sin plantearnos en ningún momento de nuestra exposición el problema de la interpretación de la concepción saussureana de lo arbitrario, y más que el del establecimiento de sus fuentes y precursores y sus relaciones con la tradición, su influencia en la lingüística posterior.

La segunda parte de nuestro artículo, que abarca el apartado 5., contendrá, en primer lugar, el análisis e interpretación de la teoría de la motivación lingüística tal como es formulada por Saussure, para, basándonos, como en el caso anterior, en las fuentes bibliográficas pertinentes, por una parte, determinar qué aspectos de los expuestos han sido recogidos por Saussure de entre los que se encuentran en la tradición y cuáles no figuran registrados y pueden, por tanto, ser considerados, al menos en un principio, originales de Saussure, y, por otra, llevar a cabo el estudio comparativo del tratamiento de la teoría de la motivación lingüística por parte de Saussure y el que ofrecen otros autores posteriores -concretamente, S. Ullmann, 
P. Guiraud y K. Baldinger-y poder así deslindar qué cuestiones de las que habremos considerado antes como propias saussureanas han ejercido alguna influencia en la lingüística posterior, pues se encuentran expuestas también en estos otros semantistas que tratamos, y delimitar de cuáles de estos postulados se hace notar que su origen o, al menos, su mención, se encuentra también, total o parcialmente, en la obra del lingüista ginebrino. Los resultados obtenidos nos permitirán trazar las conclusiones que figuran expuestas en el apartado 6 de este trabajo.

Pero antes vamos a indicar, en esta introducción, que nos referiremos al $C L G$ siguiendo la traducción, ya clásica en el mundo hispánico, realizada por A. Alonso a partir de la edición publicada por Ch. Bally y A. Sechehaye tomando como base, como es sabido, para la reconstitución y síntesis del pensamiento de F. de Saussure, el tercero de los cursos (1910-1911) impartidos por éste ${ }^{2}$, si bien somos conscientes de que el proceder de los editores no ha estado exento de problemas y dificultades tanto por lo que se refiere a las condiciones particulares de la publicación, que han originado, según señala Engler (1962: 7), «qu’on n’ait pas toujours

2 Prescindiremos, por tanto, de las otras ediciones, interpretaciones propuestas a partir del texto del $C L G$ y estudios críticos realizados tanto por los exegetas saussureanos como por otros autores más en desacuerdo con las teorías sobre el lenguaje y la lingüística supuestamente elaboradas por el propio Saussure, interpretaciones y estudios críticos que están centrados, generalmente, como bien señala Godel (1974-75: 79), sólo en los que han sido denominados «thèmes saussuriens», esto es, el principio de la arbitrariedad del signo lingüístico; la naturaleza abstracta de las entidades de la lengua, y las famosas dicotomías saussureanas de lengua / habla, sincronía / diacronía, etc. En cualquier caso, muestras representativas de la bibliografía existente sobre el primero de los temas citados -el principio de la arbitrariedad del signo, que, a pesar de que, según Saussure ( $\left.{ }^{21} 1981[1916]: 130\right)$, «no está contradicho por nadie», es, como bien indica Engler (1962: 7), la afirmación del CLG más controvertida y más debatida-, al que nos referimos concretamente ahora porque, como hemos indicado, es el basamento del que se extrae el asunto en torno al cual gira nuestro artículo, que es además el más desarrollado por la crítica de entre todos los aspectos que entraña el principio de la arbitrariedad, se encuentran, sobre todo, a) en Engler (1962: 12-37), quien, para cumplir su objetivo de examinar el principio de la arbitrariedad del signo tal como es presentado por el $C L G$, la crítica y las fuentes manuscritas y notas personales de F. de Saussure, procede a la revisión, y ulterior interpretación, de aquellos estudios críticos que contienen alguna referencia, aunque sea breve, relativa a este tema, para determinar que los puntos que, en relación con el mismo, parece que se prestan más a la controversia y que han de ser resueltos a partir de las fuentes, son: 1) el lugar que ocupa el principio de la arbitrariedad en el sistema lingüístico construido por Saussure; 2) si de lo que se trata es de la arbitrariedad del signo, de la del significante o de la del lazo que une significante y significado; 3) la delimitación entre arbitrariedad del signo lingüístico, necesidad del lazo y psiquismo; 4) la relación signo y objeto, y 5) la terminología empleada por Saussure; b) en Engler (1964: 25 n. 1), trabajo que viene a completar el repertorio bibliográfico anterior, dando lugar estas nuevas referencias citadas ahora sobre el principio de la arbitrariedad a la exposición de ciertas consideraciones generales por parte de este autor en las que, por una parte, intenta interrelacionar -y hasta conciliar-cuestiones relativas a la terminología propuesta y utilizada por unos y otros y el sentido en que cada uno de estos términos debe ser interpretado, de tal manera que resulte provechosa su conservación, y, por otra, se pronuncia respecto a las denominadas motivación fónica, relativa y semántica, que considera como fenómenos propios de signos que son, en primera instancia, arbitrarios y convencionales, frente a muchos otros signos que resultan ser, desde todos los puntos de vista, totalmente inmotivados, y respecto a las relaciones entre lengua y habla, para concluir en la distinta naturaleza que presenta el lazo que une la imagen acústica y el concepto del signo lingüístico según se considere éste en la lengua o en el habla, y c) en Koerner (1972a), obra que tiene su continuación en Koerner (1972b), reseñada en Godel (1973), la cual es una revisión y actualización de la anterior, fundamentalmente, de la sección dedicada a «The concept of the language sign, its bilateral nature and (allegedly) arbitrary character; the notion of «valeur linguistique»; semantics and semiotics» y que, según interpreta Godel (1973: 61) a partir de las indicaciones del propio Koerner, «paraît destinée avant tout au jeune chercheur qui aura le courage d'entreprendre une étude d'ensemble sur les développements récents -heureux ou malheureux- de la pensée saussurienne». 
bien lu ni bien compris le CLG» e incluso «certaines meprises» respecto a éste, como, sobre todo, por el hecho de que en el $3^{\circ}$ curso, a diferencia de lo que sucede en el $2^{\circ}$, de 1908-1909, no está clara la relación de la Lingüística con la Semiología en tanto que ciencia general de los signos, observándose interferencias entre el punto de vista semiológico y el propiamente lingüístico, hasta tal extremo que se pasa, sin advertirlo, de la distinción entre signos arbitrarios y signos simbólicos, la cual concierne a los signos en general, a la distinción entre signos absolutamente arbitrarios y signos relativamente arbitrarios, que sólo atañe a los signos lingüísticos, confusión esta de indudable interés y repercusiones para el tema que nos ocupa. Como ejemplo ilustrativo de estos aspectos enunciados, parece procedente mencionar ahora que Engler (1962: 40, 42-43) confecciona dos tablas en las que agrupa las fuentes manuscritas saussureanas que tratan el principio de la arbitrariedad del signo lingüístico según los criterios de su utilización en el CLG (tabla II: 40) y el orden cronológico y contextual de la exposición del principio de la arbitrariedad del signo lingüístico en las fuentes manuscritas saussureanas (tabla III: 42-43). La conclusión a la que llega Engler a partir de la comparación de ambas tablas es que el orden seguido por los editores del $C L G$ no se corresponde con el de las fuentes manuscritas, lo que se justifica plenamente, según el autor citado, si tenemos en cuenta la falta de relación entre los textos de Saussure y las continuas interrupciones de la exposición sobre diversas materias que se observan en las notas personales dejadas por éste, que han obligado a Ch. Bally y a A. Sechehaye a una reconstrucción, aunque según Godel (1974-75: 80) siguiendo el orden lógico, de las ideas del maestro ginebrino. En cualquier caso, a Engler (1962: 61-62) el estudio comparativo del CLG, las fuentes manuscritas y los textos que recogen la discusión suscitada posteriormente sobre la teoría de la arbitrariedad del signo lingüístico le revela que los editores han expuesto fielmente las enseñanzas de Saussure y han mantenido las grandes líneas y directrices trazadas por éste, si bien pueden advertirse ciertos errores, debidos fundamentalmente a pretendidas unificaciones terminológicas. Asimismo, en relación con la elección del $3^{\circ}$ curso impartido por Saussure para la elaboración del $C L G$, se ha de tener en cuenta, por ejemplo, que, tal como afirma Godel (1974-75: 80,84) y se observa en la distribución de los manuscritos saussureanos que figura en Saussure (2004[2002]), la idea de la limitación de lo arbitrario es una de las cuestiones que en el $3^{\circ}$ curso se presentan como nuevas, pues no aparece ni en los dos primeros ni en las notas manuscritas, lo que explica también que Saussure no la desarrollara de un modo lo suficientemente amplio como para resolver todos los aspectos implicados, a la vez que avala la decisión de los editores de basarse, para llevar a cabo su labor, en este curso y no en los dos anteriores.

2. Pues bien, de acuerdo con el esquema trazado en el apartado anterior, empezaremos nuestra exposición indicando que, a pesar de que, por lo común, en la lingüística actual se considera como aportación propia de Saussure $\left({ }^{21} 1981\right.$ [1916]), parece (cfr. Coseriu, 1977[1967]; 1986[1973]: 26-27) que el origen de la llamada teoría de la arbitrariedad del signo lingüístico $^{3}$ ha de ser situado en Aristóteles. En consecuencia, hay que considerar al filósofo esta-

3 Para referencias de autores que atribuyen a F. de Saussure el hecho de haber formulado, por primera vez, expresamente la que, por tanto, presentan como noción y teoría moderna de la arbitrariedad del signo lingüístico, cfr. Coseriu (1977[1967]: 13-15). En el mismo sentido se manifiestan también, entre otros, al menos, Guiraud ( ${ }^{9} 1969$ [1955]: 23; 1981[1960]: 20), Lázaro Carreter ( ${ }^{3} 1987[1953]:$ 56, s. v. Arbitrario (Signo)) y Lyons (1980[1977]: 96), quien, tras afirmar que Saussure hizo de la que él mismo denominaba «la arbitrariedad del signo lingüístico» uno de los 
girita como el primer y más brillante defensor de dicha teoría y quien planteó inicialmente, respecto al funcionamiento, y no en cuanto al origen, del denominado ya en nuestra época signo lingüístico, su inmotivación natural -el signo lingüístico no está motivado ni es necesario por naturaleza- junto a su motivación histórica -el signo lingüístico funciona como tradicionalmente establecido y, por tanto, como históricamente motivado-. Sin embargo, sí le debemos al maestro de Ginebra el que, al menos en el ámbito de la lingüística moderna, fuera el primero que, tras ofrecer su definición de signo lingüístico (cfr. Saussure, ${ }^{21} 1981$ [1916]: 127-130, esp. pág. 129) y determinar el que considera como el más importante de los caracteres asignados a éste por él mismo y el primero de sus dos principios fundamentales -pues, en efecto, incluso antes de aludir, aunque no respecto al signo en su totalidad sino sólo para el significante, al carácter lineal del mismo, se refiere (cfr. Saussure, ${ }^{21} 1981$ [1916]: 130-133) al hecho de que «el signo lingüistico es arbitrario» (Saussure, ${ }^{21} 1981$ [1916]: 130)-, estableciera explícitamente (cfr. Saussure, ${ }^{21} 1981$ [1916]: 219-222), con relación al principio de la arbitrariedad propio del sistema de la lengua, una limitación -con la cual, evidentemente, incluye una atenuación importante en el rigor de su primer principio, si bien es el factor que contribuye a explicar específicamente qué es lo que hace de la lengua un sistema-y distinguiera entre una arbitrariedad absoluta y una arbitrariedad relativa. De acuerdo con esta distinción, aunque todos los signos lingüísticos son realmente arbitrarios, esto es, 'inmotivados'4, sólo

principios fundamentales de su teoría lingüística, indica que este principio o teoría saussureana de la arbitrariedad de la relación entre forma y significado ha venido siendo aceptada por la mayoría de los lingüistas, incluidos aquéllos que no aceptan el concepto saussureano de signo lingüístico. No obstante, Benveniste ( ${ }^{2} 1972$ [1939]: 49) matiza la consideración expuesta al afirmar que «es de F. de Saussure de quien procede la teoría del signo lingüístico actualmente afirmada o implicada en la mayoría de los trabajos de lingüística general» (las cursivas son nuestras). En cualquier caso, se ha de tener presente que el mismo Saussure $\left({ }^{21} 1981\right.$ [1916]: 142) indica que el carácter arbitrario de los signos fue ya señalado por Whitney, aunque éste, según el lingüista ginebrino, no detectó que por ese carácter se distingue la lengua de las otras instituciones sociales. A partir de la referencia explícita de Saussure a esa fuente, Godel (1957: 194) afirma que el autor suizo tomó su noción de arbitrariedad de Whitney, quien, sin embargo, distinguía entre arbitrario y convencional, término este usado también por Saussure, según determina Engler (1962: 60-61) a partir del examen de las notas personales de Saussure, antes de 1900, aunque como equivalente de arbitrario, que, sin embargo, aunque apenas aparece en las notas personales, llega a ser el término clave en los tres cursos impartidos por Saussure, quien emplea además los de inmotivado (cfr. al respecto n. 4 de este trabajo), independiente, libre, fortuito.

4 Respecto a esta identificación del termino inmotivado con el de arbitrario y su inclusión tanto en este apartado del $C L G$ en el que el signo lingüístico es considerado en estado aislado (cfr. Saussure, $\left.{ }^{21} 1981[1916]: 131\right)$ como al hacer referencia a la evolución fonética, morfológica, etc. a las que se ven sometidas las onomatopeyas de la lengua (cfr. Saussure, ${ }^{21} 1981$ [1916]: 132), son diversos los autores (cfr. Engler, 1962: 41-49 y Godel, 1973: 62; 1974-75: 80) que se han manifestado en contra del proceder de los editores de la obra saussureana, a los que consideran responsables tanto de la desafortunada introducción del término mencionado en esos fragmentos como de considerar en la primera cita que este término no califica más que al significante, pues se explica que éste «es arbitrario con relación al significado, con el cual no guarda en la realidad ningún lazo natural», introduciendo así un tercer elemento -la realidad- en la consideración de las propiedades del signo lingüístico, mientras que en la segunda cita el ser inmotivado es delimitado como un carácter del signo lingüístico en general (cfr. sobre esto también n. 9 de este artículo). A este respecto, Engler $(1962: 41,44)$ determina que se trata de la intrusión, ejecutada por Ch. Bally y A. Sechehaye, de uno de los términos utilizados por Saussure a finales del $3^{\circ}$ curso en el apartado dedicado a su explicación del mecanismo de la lengua, en el que incluye la distinción entre lo arbitrario absoluto y lo arbitrario relativo e importantes consideraciones sobre la motivación relativa o limitación de lo arbitrario, noción esta que introduce en este momento (cfr. Saussure, ${ }^{21} 1981$ [1916]: 219-222), empleando el término inmotivado (cfr. Saussure, ${ }^{21} 1981$ [1916]: 219) al fijar su atención en la posible relación existente entre los signos de la lengua, mientras que los editores an- 
un conjunto de estos signos lingüísticos pueden ser considerados radical o absolutamente arbitrarios, «ya que en otros interviene un fenómeno que permite reconocer grados ${ }^{5}$ en lo arbitrario sin suprimirlo: el signo lingüístico puede ser relativamente motivado» (Saussure, ${ }^{21} 1981$ [1916]: 219) ${ }^{6}$. Desde nuestro punto de vista, al establecer tal delimitación y, por una parte, adoptar Saussure una perspectiva exclusivamente funcional y no la genética concerniente al origen de los signos y, por otra, centrar su atención exclusivamente en la relación o lazo existente entre el significado y el significante, quedaban superadas determinadas controversias filosóficas de raíces muy antiguas en la tradición, como son, entre otras, al menos, las dos conocidas polémicas o dicotomías -en cierto modo relacionadas, aunque representando puntos de vista muy distintos y opuestos- que, respecto a, fundamentalmente, la lengua grie-

ticipan su aparición en el $C L G$ utilizando ya el mencionado término en el apartado dedicado a la Semiología, en el que se consideran los signos aisladamente, y éstos habían sido calificados por Saussure primero de arbitrarios.

5 Aspecto este de los grados en la motivación relativa o limitación de lo arbitrario que, sin embargo, no es precisado ni desarrollado por Saussure, quien, como quedará expuesto en el apartado 5. de este artículo, se limita a establecer una distinción entre las palabras analizables -las relativamente arbitrarias o motivadas- y las no analizables -las absolutamente arbitrarias o no motivadas- pero sin marcar ninguna gradación en el conjunto de las primeras en lo que concierne a su motivación, si bien la escala de ésta no resulta en ocasiones difícil de precisar al examinar determinados ejemplos del maestro suizo, y así couperet resulta con un grado de limitación de lo arbitrario menos elevado que palabras como portier, autrefois o fréquemment, de formación regular. Posteriormente, también Ullmann ( ${ }^{2} 1976$ [1962]: 92) hace alusión al 'grado' cuando menciona la existencia en las lenguas de palabras que son motivadas y transparentes (cfr. apartado 3.1.1. de nuestro trabajo), sin ocuparse tampoco este autor de aclarar ni ejemplificar en qué sentido debe interpretarse esta alusión a la escala de gradación en la motivación de las palabras. Ahora bien, lo que, al menos desde nuestro punto de vista, sí debe quedar claro en este momento es que el punto de partida de Saussure es que todos los signos lingüísticos son arbitrarios, aunque no en el mismo grado. Para puntualizar esta cuestión nos permitimos reproducir la objeción planteada por Godel (1974-75: 88-89) a la idea de Frei (1974: 126) respecto a que «le moins que l'on puisse dire est que toute déduction que l'on voudra tirer du principe de l'arbitraire du signe devra désormais s'accompagner de la réserve: «dans la mesure oú le signe est arbitraire»»», que le lleva a aquél a preguntarse «Quelle est cette mesure?» para él mismo responderse: «Elle ne peut sans doute se réduire à zéro: en disant «arbitraire relatif», «limitation de l'arbitraire», Saussure ne voulait certainement pas dire que l'arbitraire fût jamais aboli».

6 Que, al menos en lo que concierne a la lingüística, las distinciones a las que aludimos fueran formuladas por primera vez por F. de Saussure lo manifiestan explícitamente, entre otros, Bally ( ${ }^{4} 1965$ [1932]: 127), que afirma que «l'opposition établie par F. de Saussure entre signes arbitraires et signes motivés est une de celles qui jouent le plus grand rôle dans la théorie des systèmes linguistiques» (las cursivas son nuestras); Zawadowski (1958: 927-928, 937), que se refiere a que fue Saussure quien introdujo los términos immotivé («sinónimo» o equivalente para él de los términos convencional o arbitrario) y motivé (equivalente, por tanto, en la terminología saussureana, a no convencional o no arbitrario) con su significado lingüístico, que difiere de su sentido coloquial, por el que algo «motivado» no siempre es «no convencional» y aquello que es «inmotivado» no implica que sea «convencional», si bien, según este autor, Saussure utiliza los términos immotivé y motivé, inconscientemente, tanto en su sentido lingüístico como en su sentido coloquial, lo que, indudablemente, origina confusiones en la comprensión de su teoría; Ullmann ( $\left.{ }^{2} 1976[1962]: 105 ; 1977[1964]: 50\right)$, quien indica que fue Saussure quien formuló por primera vez el principio de la motivación relativa, y Lyons (1980[1977]: 100), quien considera que el término más adecuado para hacer referencia a la relación no arbitraria entre forma o significante y significado es, precisamente, el de motivado, que fue acuñado por Saussure y empleado después por muchos otros lingüistas. No obstante, como desarrollaremos más tarde (cfr. apartados 5.2.1. y 5.2.2.), la idea en sí no es reconocida por todos como original de Saussure, sino que, aunque fuera del ámbito de la lingüística moderna, se podría encontrar, según Coseriu (1977[1967]: 61), ya en la Antigüedad Clásica - probablemente en Varrón, de quien la toma Oliveira (1981[1536], cap. 39)- o, según Frei (1974: 123 n. 7), por primera vez en el Dialogus de Leibniz, de 1677, en quien se inspiraría C. Wolff para exponerla en su Philosophia prima, de 1730, si bien Coseriu (1977[1967]: 61) plantea objeciones a la supuesta influencia leibniziana sobre Wolff en este aspecto. 
ga, se dieron ya en la Antigüedad, en concreto, la que se entabló, en primer lugar, entre los que defendían que la fundamentación de la relación entre las formas y los significados de las palabras radicaba en la naturaleza de las cosas a las que las palabras se refieren y los que sostenían que se basaba en la convención o acuerdo tácito ${ }^{7}$, y la surgida más tarde entre los que, tanto para la lengua misma como para la comprensión de su funcionamiento, propugnaban el principio de la regularidad o analogía, y en este sentido la existencia de reglas, frente a los sustentaban el de la irregularidad o anomalía como elemento dominante en las lenguas ${ }^{8}$.

3. Como prueba del hecho de que, con relación al significado, el significante no guarda en la realidad ningún lazo natural -por lo que, respecto al significado, el significante del signo es arbitrario o inmotivado- (cfr. Saussure, ${ }^{21} 1981$ [1916]: 131), así como de que no hay ninguna relación, parecido o vínculo entre el significante y el significado del signo -por lo que la relación significante-significado es arbitraria o, simplemente, puesto que el signo lingüístico resulta precisamente de la asociación de un significante con un significado, «el signo lingüístico es arbitrario» (Saussure, ${ }^{21} 1981$ [1916]: 130)- ${ }^{9}$ (la idea de sur podría estar representada

7 Son numerosos los lingüistas que, como manifiesta Engler (1962: 7, 7 n. 3), han relacionado el principio saussureano de la arbitrariedad del signo lingüístico con el antiguo debate $\varphi v ́ \sigma \varepsilon l ~ / ~ \theta \varepsilon ́ \sigma \varepsilon l$, hasta tal punto que A. H. Gardiner (1944. «De Saussure's analysis of the «signe linguistique»». Acta Linguistica 44.107-110) parece considerarlo la única respuesta posible para el mismo (cfr. Engler, 1962: 28), si bien hay que procurar establecer, como postula Engler (1964: 25-26) siguiendo a A. Pagliaro (1952. Il segno vivente. Saggi sulla lingua e altri simboli, 116. Napoli, Ed. Scient.), una distinción al menos en la terminología, ya que, como hemos señalado en el texto, Saussure formula el principio de la arbitrariedad sólo respecto al lazo que une el significado y el significante del signo, mientras que la dicotomía $\varphi v ́ \sigma \varepsilon l$ / $\theta \varepsilon ́ \sigma \varepsilon l$ está centrada en la relación entre el signo y la realidad a la que éste se refiere, con especial atención a la intervención del conocimiento humano en el esclarecimiento de esta relación. En cualquier caso, como muestras representativas de que la formulación del principio de la arbitrariedad del signo lingüístico se entiende co-

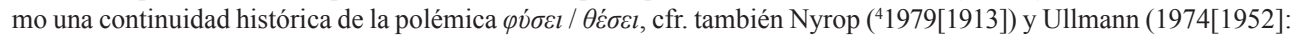
134-135; ${ }^{2} 1976[1962]:$ 91-92; 1979[1973]: 14-16).

8 Para el desarrollo de las ideas fundamentales en torno a estas dos tendencias polémicas protagonizadas por los naturalistas y los convencionalistas, por una parte, y por los analogistas y los anomalistas, por otra, cfr. Díaz Hormigo (2003a: 70-72, 155-156, y 159-162 para referencias bibliográficas sobre lo expuesto), Lyons (1977[1968]: 4-8) y Robins (1974[1967]: 28-32), así como Nyrop ( ${ }^{4} 1979$ [1913]) para un resumen del desarrollo histórico de la primera controversia mencionada.

9 El ser arbitrario es entendido por Saussure, por tanto, como una característica tanto del significante del signo lingüístico, que no presenta ningún nexo de conexión con el significado, como del signo lingüístico, en tanto que éste consiste en la asociación de un significante con un significado, si bien Godel (1957: 243; 1962: 52) intenta justificar la aparente contradicción existente entre estas dos acepciones en las que es empleado el término arbitrario en el CLG recurriendo a los argumentos de, por una parte, el didactismo de F. de Saussure, que le lleva a una simplificación del enunciado y a aludir sólo a la arbitrariedad del significante y no a la del lazo que une significante y significado, y, por otra, el de la legítima evolución del pensamiento saussureano, ya que la teoría de la determinación recíproca de valores, que por sí misma justificaría el carácter arbitrario del lazo que une el significante y el significado, es enunciada sólo en las últimas lecciones del $3^{\circ}$ curso, impartido en 1910-1911. No obstante, interesantes matizaciones a la interpretación de la teoría saussureana de la arbitrariedad del signo lingüístico han sido realizadas, entre otros, al menos, por Benveniste ( ${ }^{2} 1972$ [1939]) y por Coseriu ( ${ }^{3} 1978[1973]:$ 24-25, 24 n. 38). En efecto, el lingüista francés defiende la tesis de que el nexo existente entre significante y significado no es arbitrario, sino necesario, ya que, significante y significado, «los dos juntos han sido impresos en mi espíritu; juntos se evocan en toda circunstancia» (Benveniste, ${ }^{2}$ 1972[1939]: 51), siendo lo realmente arbitrario que tal signo lingüístico y no tal otro se aplique a un determinado elemento de la realidad y no a cualquier otro. Por su parte, para el lingüista rumano la teoría saussureana de la arbitrariedad está basada en un doble equívoco, ya que, por una parte, desde un punto de vista objetivo, el signo lingüístico se presenta como arbitrario (no motivado) naturalmente, pero como necesario (motivado) históricamente, y, por otra, desde un punto de vista subjetivo, el signo lingüístico se presenta como 
por cualquier secuencia de sonidos y no necesariamente por la secuencia $s-u-r$ que le sirve de significante), menciona Saussure $\left({ }^{21} 1981\right.$ [1916]: 130) explícitamente sólo las diferencias constatables entre las lenguas en lo que se refiere a la diversidad de significantes existentes para, supuestamente, un mismo significado y la existencia misma de lenguas diferentes (así, el significado 'buey' tiene significantes diferentes a ambos lados de la frontera franco-española - bwéi y böf (boeuf) - y también otro distinto al otro lado de la frontera franco-germana -oks (Ochs)-). Ahora bien, en distintos apartados del CLG, fundamentalmente en aquéllos en los que se procede a la mención y tratamiento de las diversas características atribuidas por el autor citado al signo lingüístico, se indica que algunas de estas características derivan o son consecuencia del carácter arbitrario del signo lingüístico, por lo que pueden ser consideradas e interpretadas asimismo como argumentos que demuestran la inexistencia de vínculo entre significante y significado. En concreto, nos referimos a los factores que originan el que se puedan formular como cualidades propias del signo lingüístico tanto la inmutabilidad como la mutabilidad de la relación significante y significado, así como al hecho de que el signo lingüístico sea considerado como portador de un valor (cfr. Saussure, ${ }^{21} 1981$ [1916], esp. págs. 137-138, 140-142, 193). Al hacer referencia a los dos primeros aspectos, Saussure deja bien marcado el alcance de su principio tanto en la perspectiva sincrónica (inmutabilidad del signo) como en la perspectiva diacrónica (mutabilidad). En efecto, una de las razones que explican que el signo lingüístico sea inmutable -esto es, que por libre voluntad de los hablantes no pueda ser ni cambiada ni alterada ni modificada la relación significante-significado, por lo que, por tanto, para la comunidad lingüística que lo emplea, tal relación se presenta como intangible- es su carácter arbitrario, ya que, al no existir un nexo de conexión racional entre significante y significado, no hay razón alguna para preferir un significante y no otro para un determinado concepto o significado (así, por ejemplo, no hay motivo alguno para preferir sœur a sister o a hermana, Ochs a bœuf o a buey). Sin embargo, aunque la masa lingüística no puede cambiarla, el factor tiempo -o mejor dicho, el transcurso del tiempo- sí puede alterar la relación significante-significado, hecho este que también es una consecuencia del carácter arbitrario del signo lingüístico, pues, al no existir ninguna motivación natural en la relación entre significante y significado, a través del tiempo y por causa de diferentes factores de alteración, pueden producirse cambios fonéticos en el significante del signo lingüístico y/o cambios de sentido que afecten al concepto significado (por ejemplo, el latín necāre 'matar' ha evolucionado al francés noyer 'ahogar' y al español anegar, por lo que se observa que han cambiado tanto la imagen acústica como el concepto), cambios que, combinados o no, conducen, inevitablemente, a un desplazamiento de la relación entre los dos planos del signo lingüístico. Asimismo, que el signo lingüístico tenga un determinado valor y que los valores de los signos lingüísticos sean relativos o diferenciales los unos con respecto a los otros no son más que consecuencias de la arbitrariedad de la relación (del lazo) que une una idea o concepto a una imagen acústica determinada, ya que el establecimiento de valores depende

arbitrario para el saber científico pero como no arbitrario para el denominado saber originario o «conciencia ingenua de los hablantes». De este modo, según Coseriu ( ${ }^{3} 1978$ [1973]: 24 n. 38), «lo que cabe decir es que el signo no es (y no puede ser) motivado causalmente; pero es motivado finalísticamente, pues corresponde a la finalidad significativa del hablante». En cualquier caso, son diversos los autores que plantean que para hallar una posible solución al problema de la necesidad / arbitrariedad de la relación entre el significante y el significado han de tenerse en cuenta las distinciones entre lengua y habla (cfr. las referencias a las que se remite en Engler, 1962: 39, así como Engler, 1964: 31-32) y entre sincronía y diacronía (cfr. Koerner, 1972b: 22 y Godel, 1973: 61). 
del uso de estos signos por parte de la colectividad a partir del consenso general, y en ningún caso el valor de un signo lingüístico puede ser fijado por un solo individuo. Ahora bien, mientras que los argumentos de la diversidad geográfica y temporal de las lenguas y el de la inmutabilidad de la relación significante-significado no eran novedosos ${ }^{10}$, la prueba de la relatividad y diferencialidad de los valores de los signos lingüísticos, que es formulada por Saussure a partir del concepto de «valor lingüístico» elaborado por él mismo, sí puede ser considerada una aportación original de este autor a la lingüística posterior.

3.1. Pues bien, al menos dos de estas razones citadas explícita o implícitamente por Saussure para defender el carácter arbitrario del signo lingüístico han sido retomadas y utilizadas por lingüistas posteriores, que, sin mencionar al maestro ginebrino ni tampoco a ninguna de sus posibles fuentes o predecesores, las esgrimen también argumentos para demostrar el carácter convencional o arbitrario de los signos de la lengua.

3.1.1. Sirva como ejemplo, entre otros, Ullmann (1949: 127; 1963[1951]: 35-36; 1974[1952]: 135-136; ${ }^{2} 1976[1962]:$ 92-93), quien, tras reconocer la existencia en las lenguas de palabras que son arbitrarias, opacas, convencionales e inanalizables, además de otras que son, al menos en cierto grado ${ }^{11}$, autoexplicativas, motivadas y transparentes ${ }^{12}$, expone tres argumentos - uno de carácter descriptivo (el cual surge de la adopción de un punto de vista sincrónico), otro histórico (que resulta de un análisis realizado desde una perspectiva diacrónica) y un tercero de índole comparativa (que implica el estar situados en el plano pancrónico), respectivamente- para confirmar la convencionalidad o arbitrariedad de muchas palabras de la lengua, consistiendo precisamente los dos últimos, esto es, los de naturaleza histórica y comparativa, en dos de las razones apuntadas ya por Saussure para defender la arbitrariedad del signo lingüístico, concretamente, las referidas a la variedad y la mutabilidad de las lenguas. En efecto, según S. Ullmann, si hubiera un enlace entre el significante y el significado, o, «to use a simplified terminology» (Ullmann 1949: 127), entre el nombre o sonido y el sentido, ambos elementos permanecerían inalterables a lo largo de la historia, pero es un hecho constatado que ambos evolucionan, y las distintas lenguas tienen palabras diferentes para designar un mismo objeto o noción, lo que no sería posible si hubiera una relación natural e intrínseca entre el nombre, sonido o significante y el sentido o significado $^{13}$. Pero además de estos dos argumentos referidos a la diversidad geográfica (espacial) y temporal de las lenguas, Ullmann apunta que si hubiera una conexión entre el nombre,

10 En efecto, según Coseriu (1977[1967]: 52-53, 54-55), a la existencia de la diversidad de lenguas se refieren, con la misma finalidad que Saussure, implícitamente Aristóteles y explícitamente Hobbes, Locke, Wolff, Jouffroy, Madvig, Whitney, Baudouin y Porzeziński; a la mutabilidad de las lenguas, Madvig, Whitney y Baudouin, y a la inmutabilidad, a partir de lo establecido por el lingüista rumano, podríamos interpretar que Locke y Madvig. No obstante, en relación con el primer argumento, vid. Frei (1974: 128), quien se refiere a la existencia de una diversidad no siempre tan absoluta o total entre las lenguas, sino, por el contrario, la constatación de ciertas semejanzas que, al menos, pueden ser interpretadas como muestras del denominado parenté élémentaire y, por tanto, como indicios de limitación de lo arbitrario.

11 De nuevo la referencia al 'grado' en la arbitrariedad / motivación de los signos lingüísticos que ya formuló Saussure ( ${ }^{21} 1981$ [1916]: 219), sin aclarar ni ejemplificar Ullmann, como tampoco lo hizo Saussure (cfr. n. 5 de nuestro estudio), en qué sentido ha de interpretarse este aserto.

12 Aserción esta que figura también en Ullmann (1959: 331-332; 1977[1964]: 79; 1979[1973]: 16).

13 En estos argumentos se basa precisamente García Manga (2002: 161-162) para delimitar dos tipos de convencionalidad o arbitrariedad del signo lingüístico: la denominada arbitrariedad contrastiva, de carácter interlingüístico, constatable, por tanto, a partir del análisis simultáneo y comparativo entre lenguas distintas, y la arbitrariedad 
sonido o significante y el sentido o significado, los mismos sonidos significarían siempre la misma cosa y, a la inversa, la misma cosa sería designada siempre por los mismos sonidos, y, sin embargo, existen palabras homónimas, sinónimas y cuasisinónimas. Este razonamiento carecería absolutamente de una base sólida para F. de Saussure, desde el momento en que, a pesar de que no expresa ningún juicio explícito al respecto, de su concepción dual y simétrica del signo lingüístico (cfr. Saussure, ${ }^{21} 1981$ [1916]: 128-129), se infiere que el lingüista suizo no admite la existencia ni de homonimia/polisemia ni de sinonimia en una lengua, aunque de las razones que derivan, fundamentalmente, de su principio de que «en la lengua no hay más que diferencias» (Saussure, ${ }^{21} 1981$ [1916]: 203) y de su afirmación, que se justificaría por el que actualmente denominamos principio de la economía lingüística, de que «la lengua se resiste a mantener dos significantes para una misma idea» (Saussure, ${ }^{21} 1981$ [1916]: 263), se deduce también que no admite la existencia de sinonimia. En cualquier caso, los tres argumentos citados por Ullmann habían sido formulados antes, y con la misma finalidad, por Nyrop ( ${ }^{4} 1979[1913]:$ 400-401) $)^{14}$.

3.1.2. El mismo proceder, en lo que se refiere a utilización y repetición de los argumentos saussureanos, aunque sin hacer referencia al lingüista suizo, es seguido por Baldinger (1970: 29). En efecto, en su estudio sobre, eso sí, la relación existente entre los significantes de los signos lingüísticos - la forma de los signos- y la realidad, Baldinger cita como pruebas para deshacer la hipótesis de que existe una relación o una línea que conecta significante y realidad, o, lo que es lo mismo, para defender la arbitrariedad o convencionalidad del vínculo existente entre significante y realidad, los argumentos de carácter comparativo y de carácter histórico que ya habían alegado al menos Saussure y Nyrop antes que Ullmann. Así, se refiere a 1) el hecho de que el mismo objeto se designa de distintos modos, esto es, con imágenes acústicas diferentes, en lenguas distintas, por lo que para todos aquellos que han aprendido una lengua distinta a la materna está claro que entre la palabra y la realidad no existe conexión o relación directa, es decir, el significante no está en modo alguno motivado por la realidad, y 2) el hecho de que se producen cambios en las formas o significantes de las palabras, ya que si existiera un vínculo entre significante y realidad no podría alterarse la forma de una palabra, por tanto, no habría historia de la lengua.

4. Asimismo, conviene atender a que no considera Saussure como excepciones al principio de la arbitrariedad del signo lingüístico ni siquiera la existencia de onomatopeyas y de exclamaciones en las lenguas ${ }^{15}$. En efecto, respecto a estas últimas, señala (cfr. Saussure,

intralingüística, que se evidencia en el seno de una misma lengua y se encuentra avalada por los argumentos de carácter descriptivo e histórico expuestos en el texto.

14 En efecto, aunque no es mencionado por Ullmann, Nyrop ( ${ }^{4} 1979$ [1913]: 400-401) se había referido, para rebatir la concepción de que las palabras tienen una significación natural, a que 1) un mismo nombre puede designar muchos objetos y un mismo objeto puede ser designado por varios nombres; 2) las palabras cambian constantemente de sentido, llegando a veces a ser portadoras de ideas a menudo muy diferentes e incluso hasta opuestas, y 3) los objetos reciben denominaciones distintas en las lenguas extranjeras y el mismo grupo de fonemas toma un sentido diferente según la lengua que lo emplea. Ahora bien, a pesar de estas ideas, que, por otra parte, son generalmente admitidas, también este autor admite la existencia en las lenguas de palabras opacas y palabras transparentes o descriptivas.

15 Es sabido que parte de la bibliografía existente sobre el principio saussureano de la arbitrariedad del signo lingüístico se fundamenta en las excepciones con las que se pretende poner en entredicho la existencia de dicho principio, pudiendo ser citados en este sentido como representativos, por el reclamo que se hace desde sus respectivos títulos, los trabajos de Bolinger (1949) y de Frei (1974). Ahora bien, mientras que este autor plantea sus reflexiones sobre lo que, desde su punto de vista, resulta ser «le mythe de l'arbitraire absolu» a partir de su propia interpretación 
${ }^{21} 1981$ [1916]: 132-133) que la comparación entre lenguas es un criterio suficientemente demostrativo de la ausencia de vínculo real entre el significante y el significado de la exclamación que se considera (por ejemplo, cfr. alemán au!, francés ä̈e!, español ;ay!). Igualmente, en lo que se refiere a las onomatopeyas (cfr. Saussure, ${ }^{21} 1981$ [1916]: 132), arguye el lingüista de Ginebra, mezclando, como bien señala Ullmann (1949: 131; 1974[1952]: 153. Cfr. al respecto n. 16 del presente trabajo), en contra de su propia tesis, los ejes o perspectivas sincrónica y diacrónica, que a) en relación con el conjunto del léxico de una lengua, su número es escaso e inapreciable y, por tanto, no se puede considerar que sean representativas, sino más bien insignificantes; b) la interpretación o imitación de los ruidos en que consisten las onomatopeyas auténticas es sólo aproximada y convencional, y una prueba de ello es que las onomatopeyas son distintas en las diferentes lenguas (por ejemplo, cfr. francés ouaoua, alemán wauwau, español guau guau), lo que constituye la muestra más evidente de su carácter arbitrario; c) una vez instaladas en la lengua, las onomatopeyas experimentan las mismas evoluciones fonéticas, morfológicas y/o semánticas que las demás palabras no onomatopéyicas para resultar signos lingüísticos arbitrarios o inmotivados, al igual que los demás signos de la lengua (por ejemplo, la onomatopeya del latín vulgar pīpio, -onis, formada a partir del verbo onomatopéyico pīpīre 'piar', la cual imitaba el sonido de las crías de las aves y significaba 'palomito, pichoncito', y que, sin embargo, ha evolucionado al francés pigeon y al español pichón, por lo que, debido a que ha cambiado el significante, se ha perdido el supuesto vínculo con el significado que tenía en su origen, o sea, su posible motivación), y d) por el contrario, determinadas palabras que hoy en día podrían ser consideradas onomatopéyicas han llegado a adquirir este carácter imitativo de sonidos o ruidos de la realidad a partir de la evolución fonética sufrida por los respectivos significantes pero no tienen realmente un origen onomatopéyico (por ejemplo, francés fouet 'látigo' deriva del latín fāgus 'haya' y francés glas 'doblar de campanas' del latín classicum 'toque, señal dada con la trompeta'), con lo cual el número de las onomatopeyas realmente existentes en la lengua es todavía menor.

4.1. Precisamente, al valerse de forma expresa de las onomatopeyas para defender la arbitrariedad de los signos lingüísticos, queda ilustrada la manifiesta disensión existente, en lo que se refiere al menos a este aspecto de la teoría de la arbitrariedad del signo lingüístico, entre el pensamiento saussureano y el parecer tanto de gran parte de sus antecesores -muchos de los cuales vieron en la onomatopeya la forma primitiva del habla humana- como de sus coetáneos y continuadores. Ahora bien, se ha apuntado (cfr. Coseriu, 1977[1967]: 55-56) que ninguna de las pruebas que aduce Saussure para demostrar que las onomatopeyas son

de la concepción saussureana de lo arbitrario, D. L. Bolinger se basa para determinar que «the sign is not arbitrary» en ejemplos prácticos que, según él, contribuyen a demostrar, por una parte, la influencia de las formas en los significados de las palabras y, por otra, la influencia de los significados en las formas, o sea, en ambos casos, en palabras que muestran que existe conexión entre formas y significados. Concretamente, examina ejemplos en los que se observa que a) el significado altera la forma o configuración fonética de una palabra, como en la etimología popular; b) la forma o configuración fonética de las palabras altera su significado, lo que sucede, sobre todo, en muchas de las palabras inventadas, cuyo significado se establece a partir de los significados de otras palabras similares en cuanto al sonido; c) el significado mantiene o destruye la forma o configuración fonética de las palabras, como, por ejemplo, en los casos en los que uno de los significados de una forma responde, a diferencia de los otros, a un hecho de tabú y dicha forma desaparece con todos sus significados por causa de ese significado tabuizado, y d) la forma o configuración fonética de las palabras mantiene o destruye su significado, como puede suceder en los casos de conflictos de homónimos, en los que uno de los significados puede llegar a desaparecer a fuerza de no ser empleado para evitar confusiones o ambigüedades con el otro. 
elementos arbitrarios o convencionales era originalmente suya ${ }^{16}$. En cualquier caso, por una parte, Saussure, al rebatir que las onomatopeyas puedan constituir una de las posibles excepciones al carácter arbitrario del signo lingüístico, se separa abiertamente de la tesis defendida ya en la Antigüedad por los naturalistas griegos, quienes, al estudiar el origen del lenguaje y de las lenguas - por tanto, desde una perspectiva genética-, se servían, fundamentalmente, de las palabras onomatopéyicas y de las que, según la terminología actual, presentan cierto simbolismo fónico o responden a algún efecto fonoestético para defender la existencia de una conexión natural, al menos inicialmente, entre las palabras y las cosas, considerando que el origen expresivo de las onomatopeyas era un reflejo de la realidad nombrada y el matiz indicativo de su sentido verdadero. Asimismo, Bally ( ${ }^{4} 1965$ [1932]: 129-133), precisamente uno de los discípulos y sucesores más directos de Saussure y sobre el que las enseñanzas de éste ejercieron un mayor influjo -hasta tal punto de ser uno de los denominados «ortodoxos saussureanos» (cfr. Alonso, ${ }^{21} 1981$ [1945]: 10)-, se vale, entre otros elementos ${ }^{17}$, de las denominadas interjecciones, categoría en la que aúna las onomatopeyas y las exclamaciones, para demostrar que el signo lingüístico puede estar motivado desde el punto de vista del significante. Concretamente, se refiere a las 'interjecciones' que pueden equivaler a frases com-

16 Sino que se encuentran, aunque parcialmente, con el mismo propósito, al menos, en Madvig, Fortunatov, Porzeziński y Whitney. No obstante, antes que éstos, ya en el siglo XVI, Francisco Sánchez el Escéptico se había referido, en su defensa de la no existencia de correspondencia entre los nombres y las cosas y, por tanto, de que los nombres son signos arbitrarios, a las palabras onomatopéyicas para señalar que tampoco en éstas se puede hallar la naturaleza de las cosas, pues con éstas las onomatopeyas sólo tienen semejanza en cuanto al sonido (cfr. al respecto García, 1960: 40-41). Pero, ya después de Saussure, estos mismos aspectos a los que alude el maestro de Ginebra son mencionados, y aunque no en muchas ocasiones sí utilizando incluso sus mismos ejemplos, por Ullmann ( ${ }^{2} 1976[1962]$, esp. págs. 98, 107-109, 115), quien, sin embargo, también sostiene, como será expuesto en el texto de este mismo apartado, que las formaciones onomatopéyicas están motivadas fonéticamente y afirma (cfr. Ullmann, 1949: 131; 1974[1952]: 153) que Saussure, al dar esos ejemplos y menospreciar el papel del simbolismo fónico en la lengua y al inferir de sus propios argumentos que «las onomatopeyas nunca son elementos orgánicos de un sistema lingüístico» (Saussure, ${ }^{21} 1981$ [1916]: 132), está confundiendo los puntos de vista sincrónico y diacrónico, siendo éste un error que el mismo lingüista ginebrino se ocupó por primera vez de denunciar. Por su parte, Lyons (1980[1977]: 96-97) señala que la tradicionalmente denominada onomatopeya constituye una excepción «universalmente reconocida» al principio saussureano de la arbitrariedad del signo lingüístico, pero, al mismo tiempo, el lingüista inglés hace referencia, al igual que Saussure, al escaso número de onomatopeyas existentes en cada lengua $\mathrm{y}$ al hecho de que es posible observar en ellas cierta arbitrariedad o convencionalismo, ya que se construyen conforme a los sistemas fonológicos de cada una de las lenguas - de ahí que sean diferentes según las lenguas, como ya observó Saussure-, sin ser, por tanto, dichas onomatopeyas imitaciones o reproducciones exactas de la realidad que representan. Sin embargo, Benveniste ( ${ }^{2} 1972$ [1939]: 52-53), en el marco de su defensa de que el vínculo existente entre el significante y el significado del signo no es arbitrario sino necesario, mientras que la relación que une el signo lingüístico y la realidad por él designada sí es arbitraria (cfr. n. 9 de este mismo trabajo), hace también referencia a las objeciones planteadas por Saussure para demostrar el carácter arbitrario de las onomatopeyas, a las que el lingüista francés les atribuye, al igual que Saussure, los mismos caracteres que encuentra en los demás signos lingüísticos del sistema, lo que en su caso particular implica que sostiene que también respecto a éstas la relación de arbitrariedad se establece entre la onomatopeya o la palabra expresiva y el fenómeno u objeto material al que se refiere.

17 En efecto, además de a las interjecciones alude Bally $\left({ }^{4} 1965\right.$ [1932]: 130-132) a otros aspectos relativos al denominado simbolismo fónico, así como a los prosodemas o elementos suprasegmentales de la lengua, ya que se refiere a los valores expresivos de ciertos sonidos y grupos de sonidos; a los movimientos musculares de labios, lengua y mandíbulas por la articulación de un sonido o de un grupo de sonidos, la cual produce una modificación en la máscara facial que puede ser interpretada por los hablantes como relacionada simbólicamente con la idea expresada, y al valor simbólico y motivador del acento y de la entonación. 
pletas, adquiriendo, por tanto, el valor de éstas (««Vos mains sont sales; pouah!» (pouah! = «cela me dégoûte»)»); a aquéllas que, sin cambiar de forma, pasan a formar parte, por transposición hipostásica, de una determinada categoría léxica («le brouhaha, un crincrin, crier haro, faire fi, marcher cahin-caha, repondré du tac au tac, etc.»); a las que, por transposición explícita (derivación sufijal), intervienen como bases para la formación de derivados (cliqueter, cliquetis; craquer, craquement; croasser; miauler), así como a aquellas palabras que, para los hablantes, resultan expresivas por sus sonidos, puesto que se percibe una relación entre la forma fónica y la impresión causada por el sentido (cahoter, grincer, crisser, palpiter, tinter). Pero también Frei (1974: 122), otro de los principales representantes de la denominada escuela de Ginebra, encargada, no obstante, -insistimos en ello aunque es sabido- de difundir las teorías saussureanas, considera, en contra de éstas, que las onomatopeyas de las lenguas que no dominamos son algunos de los testimonios de que son signos no arbitrarios, ya que los significados de aquéllas se pueden adivinar. Tampoco el carácter inmotivado atribuido por Saussure a las onomatopeyas es compartido por muchos otros autores posteriores al maestro de Ginebra, como, entre otros, Ullmann (1949: 129; 1959: 332; 1963[1951]: 36; 1974[1952]: 138-155; ${ }^{2} 1976[1962]: 93-104 ; 1977[1964]$ : 48-49; 1979[1973]: 16-18, 45-46), Guiraud ( $\left.{ }^{9} 1969[1955]: 25 ; 1981[1960]: 19-20,21-22\right)$ y Baldinger (1970), quienes, aun admitiendo la existencia en las lenguas de palabras arbitrarias o convencionales (cfr. 3.1.), al sostener que en las onomatopeyas se intenta que se dé, al menos en un principio, una relación natural o directa entre la forma o estructura fonética de la palabra y la realidad que ésta simboliza, distinguen un tipo de motivación lingüística denominada motivación primaria, directa, absoluta, natural, fónica o fonética, característica precisamente de las onomatopeyas, las cuales, por tanto, son consideradas por dichos autores como palabras motivadas de las lenguas. En este sentido, algunos autores, como es el caso de S. Ullmann y P. Guiraud, llegan incluso a delimitar, distintos tipos de motivación fónica y, por tanto, de onomatopeyas según si la estructura fonética de la palabra imita, denota o reproduce un referente que es un sonido o ruido (las denominadas onomatopeyas primarias por Ullmann y onomatopeyas acústicas por Guiraud); si la expresividad fónica evoca un movimiento (onomatopeyas secundarias para Ullmann y fonocinéticas para Guiraud), o si la onomatopeya consiste en la asimilación de un ruido o movimiento a formas, colores, sentimientos, etc. (las onomatopeyas fonometafóricas de Guiraud y también onomatopeyas secundarias para Ullmann, ya que la expresividad fónica evoca, al igual que en caso anterior, una experiencia no acústica).

5. Por el contrario, sí encuentra Saussure ( ${ }^{21} 1981$ [1916]: 219-222) que constituyen objeciones al principio de la arbitrariedad los signos lingüísticos que, tanto según él mismo (cfr. Saussure, ${ }^{21} 1981$ [1916]: 220) como también, respecto a la concepción saussureana, apunta Bally ( ${ }^{4} 1965$ [1932]: 127), resultan de la combinación de dos o más elementos (signos) arbitrarios, pudiendo ser aquellos signos considerados, precisamente por esta razón, como parcial o relativamente arbitrarios o, lo que viene a ser lo mismo, como relativamente motivados. Así, a diferencia de veinte, diez y nueve, que son radicalmente arbitrarios o inmotivados, el signo lingüístico diecinueve no lo es totalmente, sino que presenta una motivación relativa, ya que, por una parte, evoca las palabras de las que se compone, esto es, diez y nueve (relación sintagmática), y, por otra, algunas palabras con las que la palabra diecinueve se encuentra asociada, como, entre otras, veintinueve, dieciocho, diez mil (relación asociativa). Del mismo modo, cerezo, fresno, haya, etc. son inmotivados, pero no peral, que evoca los elementos formativos de que se compone (el sustantivo pera y el sufijo $-a l$ ) y las palabras 
con las que está asociado (rosal, frutal, etc.). La existencia de palabras arbitrarias y palabras motivadas se hace también evidente tanto si se comparan parejas de formas de una misma lengua que expresan conceptos relacionados (por ejemplo, español pastor, inmotivado, y vaquero, relativamente motivado; francés gêole y cachot, hache y couperet, concierge y portier, jadis y autrefois, souvent y fréquemment, aveugle y boiteux, sourd y bossu, second y deuxième) como si se comparan parejas de formas que expresan un mismo 'contenido' en lenguas distintas (por ejemplo, alemán Laub y francés feuillage, francés métier y alemán Handwerk). En cualquier caso, y sin entrar a precisar los factores que determinan la motivación en cada uno de los ejemplos expuestos, dos son, según Saussure, los principios que implica la denominada motivación relativa, a saber, « $1^{\circ}$, el análisis del término dado, por consiguiente una relación sintagmática; $2^{\circ}$, la evocación de uno o varios términos, por consiguiente una relación asociativa» (Saussure, ${ }^{21} 1981$ [1916]: 220), ya que para el considerado por muchos fundador de la moderna ciencia del lenguaje la motivación es 'más completa' cuanto mayores sean las que, en terminología actual, podríamos considerar posibilidades de segmentación, analizabilidad y descomposición del signo en elementos formativos dotados de significado y cuanto mayores sean las posibilidades de definir de manera exacta y precisa el significado de estas subunidades constitutivas del signo ya previamente delimitadas.

5.1. Sin entrar aquí a enjuiciar las observaciones expuestas en torno a la motivación relativa por parte de Saussure ni a revisar aquellos aspectos tratados por este autor en otras partes de su obra pero que se encuentran implicados y relacionados con la misma ${ }^{18}$ y que inexcusablemente requerirían su mención si fuera nuestro objeto proceder a la valoración de la que po-

18 Tales como, entre otras cuestiones, la noción saussureana de sintagma (cfr. respecto a esta noción y su influencia en la lingüística posterior Díaz Hormigo 2003b, esp. págs. 249-250, 257, 258, 259 n. 35); su concepción de las relaciones sintagmáticas y las relaciones asociativas, así como los distintos tipos de éstas que figuran delimitados, lo que se encuentra en estrecha relación con los factores que, según el autor que tratamos, originan una limitación de lo arbitrario, pues éstos son identificados en el $C L G$ con las solidaridades que contraen las palabras en el sistema de la lengua, que pueden ser sintagmáticas y asociativas y que determinan, según Saussure, una parte del valor de las palabras relativamente motivadas, que no es igual a la suma de los valores de los elementos arbitrarios que componen dicha formación. Ahora bien, tal como observa Zawadowski (1958: 931), en ningún momento se indica en qué sentido es aquí empleado el término valor, qué parte de éste le viene dado a la palabra relativamente motivada por las solidaridades que contrae ni por qué tales solidaridades constituirían una limitación del carácter arbitrario del signo, y la importancia concedida por Saussure al mecanismo de la analogía como principio regulador de las nuevas creaciones de la lengua, aspecto este que, a su vez, ha de relacionarse, por una parte, además de con, evidentemente, la motivación relativa de las palabras a partir de las implicaciones que la aplicación del principio de la analogía conlleva, con la distinción propuesta entre palabras productivas y palabras estériles o improductivas y, por otra, con el esbozo de una tipología de lenguas según sean éstas lexicológicas o gramaticales, clasificación esta que, según Saussure, es una de las más importantes consecuencias de la aplicación del principio de la limitación de lo arbitrario, pues dicha clasificación se basa en la proporción inherente de la arbitrariedad que manifiestan las lenguas, la cual influye incluso en el procedimiento seguido por los gramáticos para el estudio de las mismas. En relación con este último aspecto, apenas esbozado por Saussure a partir de la observación de que la proporción de las palabras transparentes y opacas varía no sólo de una lengua a otra, sino también de un período a otro de la misma lengua, cfr. los valiosos comentarios de Ullmann (1949: 137-138; 1959: 332; 1974[1952]: 170-179; ${ }^{2} 1976$ [1962]: 119-130; 1977[1964]: 10-12, 80; 1979[1973]: 19-21), a propósito del francés moderno en comparación, por una parte, sobre todo con el inglés y el alemán, aunque también con el latín, el italiano y el español y, por otra, con períodos anteriores de la propia lengua francesa, formulados, no obstante, atendiendo, al igual que lo hizo Saussure (cfr. nuestras observaciones al respecto en, sobre todo, n. 27 de este estudio), sólo a la estructura morfológica de las palabras y obviando para los porcentajes todo lo que se refiere a la presencia en las lenguas de palabras onomatopéyicas, metafóricas, metonímicas o basadas en tropos similares. 
dríamos denominar teoría saussureana de la motivación lingüística (lo que implicaría atender, particularmente, a las discrepancias, incoherencias y vacilaciones que se revelan cuando se contrastan los diversos apartados del $C L G$ en los que se abordan tales cuestiones y se procede a un estudio comparado entre éste, las fuentes manuscritas y la discusión posterior instituida sobre lo arbitrario del signo), son diversos los aspectos que pueden inferirse de lo formulado por el lingüista suizo y que han de tenerse presentes para el desarrollo ulterior de lo que aquí se pretende. Así, hemos de destacar el hecho de que, mientras que el principio de lo arbitrario absoluto figura ejemplificado con palabras simples - que, por tanto, pueden ser consideradas signos absolutamente inmotivados-, los ejemplos que le parecen a Saussure más apropiados para ilustrar lo arbitrario relativo son palabras derivadas y compuestas ortográficamente, las cuales, por tanto, se deben entender como signos lingüísticos relativamente motivados. De ahí que, reformulando el aserto expresado por Frei (1974: 121) a partir de lo establecido por Saussure, pueda indicarse que la oposición entre lo arbitrario absoluto y lo arbitrario relativo radica en la ausencia / presencia de dos o más unidades lingüísticas coexistentes en el signo que se analiza. Sin embargo, en ningún lugar de su obra define explícitamente el lingüista ginebrino ni en qué consiste la motivación relativa ni qué signos lingüísticos pueden ser considerados como relativamente motivados, si bien, siguiendo el proceder al respecto de Zawadowski (1958), podemos llegar a obtener una definición exacta de motivación relativa según Saussure, la cual puede inferirse tanto de las diversas observaciones expuestas por este autor sobre la oposición entre los dos tipos de arbitrariedades en general y sobre lo arbitrario relativo en particular como, fundamentalmente, del análisis de los ejemplos de arbitrariedad relativa que figuran en el $C L G$. En este sentido, establece Zawadowski (1958) que para el lingüista de Ginebra están relativamente motivadas aquellas construcciones gramaticales cuyos elementos constitutivos contraen una relación sintagmática entre sí y presentan cierto tipo o categoría de relación asociativa con otros elementos de la lengua, concretamente, con aquéllos con los que presentan una vinculación al mismo tiempo de índole formal y semántica. En cualquier caso, con la exposición de su teoría, Saussure introduce la noción de limitación de lo arbitrario por el sistema de la lengua, que, como reconoce Frei (1974: 125-126 n. 11), es identificada con el fenómeno de la motivación, la cual, puesto que en ningún momento el maestro suizo considera que puede venir dada desde fuera del sistema de la lengua sino sólo por y dentro de éste, puede ser denominada motivación intralingüística (cfr. Coseriu, 1977[1967]: 56), característica, como hemos establecido, según la concepción y ejemplificación saussureanas, sólo de las formaciones derivadas y compuestas de la lengua ${ }^{19}$.

19 Sin embargo, nuestro análisis (cfr. Díaz Hormigo, 2006a) del fenómeno de la variación lingüística en relación con los conceptos de arbitrariedad y motivación morfológica nos permitió constatar que determinadas formaciones derivadas que son variantes lingüísticas de expresión sólo están motivadas en la variedad o modalidad lingüística en la que se emplean, pero no si atendemos a otra modalidad o variedad de esa misma lengua, por lo que la motivación morfológica no siempre y necesariamente ha de ser considerada de carácter intralingüístico. Y estrechamente relacionado con este aspecto se encuentra el hecho de que también la misma existencia y formación de derivados en una lengua es de naturaleza arbitraria y convencional, y esto no sólo se constata comparando dos lenguas distintas, como es habitual entre los estudiosos, sino también en el seno de una misma lengua si comparamos al menos dos de sus variedades o modalidades lingüísticas. A tales conclusiones llegamos a partir de nuestro estudio contrastivo y comparativo del español peninsular y el español americano (variedades o modalidades lingüísticas de una misma lengua, el español), que nos permitió demostrar que las palabras derivadas existentes en el seno de una modalidad lingüística no se corresponden, desde el punto de vista del significante, siempre y en todos los casos con palabras también derivadas en la otra modalidad lingüística, a pesar de que ambas formas compartan un contenido común, 
5.2.1. Ahora bien, la interpretación de las palabras derivadas y compuestas como relativamente motivadas, aunque sin ponerla en relación con el principio de la arbitrariedad, no es original de F. de Saussure, sino que se encuentra esbozada ya, con las obvias diferencias debidas al transcurrir de casi cinco siglos de especulación lingüística entre el desarrollo teórico de uno y otro autor, en Oliveira (1981[1536], cap. 39), quien distingue entre las dicciones que llama primeras, correspondientes a las denominadas primitivas por los gramáticos latinos, que son aquéllas que no proceden de otras sino que su nacimiento responde sólo a la libre voluntad de aquél que las impuso por primera vez, y las dicciones tiradas, llamadas derivadas por los gramáticos latinos. Según el gramático portugués, son dicciones tiradas aquéllas que están formadas de otras voces a partir de la observación de que las cosas a las que esas dicciones se refieren son o parecen sacadas de las designadas por estas voces, de tal manera que, al ser aquellas cosas consideradas descendientes o especies de las designadas por éstas, las dicciones que las designan serán también especies que participan de estas voces, por lo que se obtienen formas semejantes que vienen a reflejar la semejanza o relación existente entre los objetos de la realidad. Se citan como ejemplos tinteiro, que tiene ese nombre por su relación con la tinta; velhice, de velho, porque designa su propiedad, y hōnrada u hōnrado, de hōnrar, cuya relación reconoce F. de Oliveira no poder aclarar, sin parecerle que esto deba ser considerado un defecto. Al autor de la primera gramática de la lengua portuguesa le parece ventajosa esta manera de abastecer y hacer copiosa la lengua, ya que, al quedar reflejada la semejanza existente entre las cosas en las voces que las designan, éstas son más claras y expresan mejor sus significados: la diversidad de las dicciones muestra la diversidad de las cosas y, por el contrario, la semejanza que se pretende conseguir con las dicciones hace entender que las cosas a las que se refieren no son totalmente diferentes sino que están relacionadas. Ahora bien, la aparición de esta interpretación de las formaciones derivadas en la Gramática de F. de Oliveira lleva, lógicamente, a pensar a Coseriu (1977[1967]: 61) que el origen de esta teoría se encuentra en la Antigüedad Clásica y, en este sentido, probablemente en Varrón, quien, efectivamente, la desarrolla en su tratado De lingua latina (cfr. al respecto Varrón, 1990, esp. Libros VIII, IX y X), obra en la que, como ha sido señalado (cfr. Arens, 1975[2¹969] I: 51 y Robins, 1974[1967]: 29-30, 57), este escritor latino del siglo I a. de C. examina minuciosamente la controversia lingüística de la analogía frente a la anomalía, a la que concede un amplio tratamiento, intentando manifestar que hay que entenderla, no como dos puntos de vista antagónicos ante el mismo fenómeno, sino como dos actitudes diferentes ante el lenguaje, conciliables y justificadas en parte al menos por la evidencia, a la vez que establece una distinción entre formación por flexión y formación por derivación, diferenciación esta que, por otra parte, no es corriente en el mundo clásico (cfr. Robins, 1974[1967]: 57-58). En cualquier caso, indica Coseriu (1977[1967]: 56, 58, 61) que, de los autores anteriores a

\footnotetext{
sino que tales formaciones derivadas pueden corresponderse bien con palabras derivadas (aguador-aguatero, apisonadora-aplanadora, cajetilla-atado), o bien con palabras primitivas (amígdalas-agallones). Pero, aun en el caso de corresponderse y compartir un contenido común con palabras también derivadas en la otra modalidad lingüística, en las formaciones derivadas existentes en ambas modalidades lingüísticas, son distintos o bien los procedimientos o esquemas morfológicos en que están basados tales formaciones derivadas (agarrada-agarrón, pertrechar-apertrechar), o bien los morfemas léxicos que constituyen las bases de las respectivas formaciones derivadas (acolcharacolchonar). De ahí que, como hemos afirmado, incluso desde un punto de vista intralingüístico -y no sólo interlingüístico, como hasta ahora venía siendo establecido- podamos también reconocer, en relación con el mecanismo de la derivación, la existencia del fenómeno de la arbitrariedad y la convencionalidad del signo lingüístico.
} 
Saussure a los que el mismo lingüista rumano se refiere en su trabajo, esta consideración de las palabras derivadas y compuestas como relativamente motivadas ya aparece formulada, aunque, como es obvio, no exactamente de la misma forma en que lo hace el lingüista ginebrino, por C. Wolff, quien la expone en su Philosophia prima, de 1730, si bien no le parece al maestro de Tübingen muy probable que dicha exposición fuera conocida por Saussure.

5.2.2. Por su parte, Frei (1974: 123 n. 7) apunta que la noción de lo arbitrario relativo aparece en el Dialogus de Leibniz, de 1677, quien la explica como una correspondencia entre la conexión de los signos y la de las cosas, y que es en este filósofo en quien se inspiró Wolff para la exposición de su teoría ${ }^{20}$.

5.3. La teoría de la motivación relativa de Saussure ha sido desarrollada por semantistas posteriores al lingüista de Ginebra, los cuales, aunque han tenido en cuenta las ideas saussureanas, no siempre han remitido expresamente al $C L G$.

5.3.1. Así, por ejemplo, Ullmann (1949: 128-130; 1959: 332; 1963[1951]: 36; 1974[1952]: 136-163; ${ }^{2} 1976[1962]: 93-106 ; 1977[1964]$ : 48-50; 1979[1973]: 16-19), tras señalar que son motivadas «todas las palabras cuya forma no es puramente fortuita a los ojos del hablante» ${ }^{21}$ (Ullmann, 1974[1952]: 136), delimita tres clases de motivación según ésta resida en la estructura fonética de las palabras, en su estructura morfológica o en su fondo semántico. Por ello distingue, además de la motivación fonética, propia de las onomatopeyas y de las palabras expresivas de las lenguas (cfr. el apartado 4.1. de este artículo), la denominada motivación morfológica, a la que responden las palabras derivadas por prefijos y/o sufijos y las palabras compuestas que son sentidas como tales derivados o compuestos, pues, retomando, sin parecer advertirlo, los principios de la motivación relativa establecidos por Saussure, observa que sólo en esos casos derivados y compuestos presentan una estructura transparente que hace posible que su significado pueda ser deducido del de los elementos significativos que los componen (así, chanteur es una palabra motivada en francés porque su significado puede ser explicado a partir del verbo chanter y el sufijo - eur, que interviene en la formación de nombres de agente, y el compuesto housewife es motivado en inglés por la existencia en esta misma lengua, como palabras autónomas e independientes, de sus componentes house y wife $)^{22}$, y la llamada motivación semántica, referida a las palabras que se basan en un sentido

20 Estas afirmaciones son objeto de algunas puntualizaciones por parte de Coseriu (1977[1967]: 61), tanto en lo que atañe a cierta precisión en las declaraciones por él mismo emitidas como en lo que se refiere a la supuesta influencia leibniziana sobre Wolff. Así, por una parte, el lingüista rumano especifica que él no ha afirmado, como parece haber entendido Frei, que Wolff fuera el primero en mencionar el concepto de «arbitrario relativo», sino que se ha referido a que en este autor se encuentra la interpretación de las palabras derivadas y compuestas como relativamente motivadas, $y$, a este respecto, tampoco ha dicho que Wolff fuera el primer autor en ofrecer tal interpretación, sino sólo que, cronológicamente, es el primero de los autores tratados por él en su artículo que considera a las palabras derivadas y compuestas como relativamente arbitrarias. Y, por otra parte, Coseriu aclara que, aunque conoce y admite que Leibniz influyó en Wolff, en lo tocante a la teoría de la arbitrariedad, las ideas de Wolff no están tomadas de Leibniz sino de la tradición escolástica.

21 De tal manera que "to decide whether a name is conventional or motivated, the following question will have to be answered: Is there any intrinsic and synchronistically valid reason for it to have that form and no other? If there is, however vague or limited it may be, the name will be at least partially motivated; if there is not, it will be purely conventional" (Ullmann 1949: 128).

22 En este sentido, nos parecen particularmente interesantes las precisiones introducidas explícitamente por Ullmann, basándose, no obstante, en los dos principios que, según Saussure, implica la motivación relativa, ya que, tal como ya expusimos en otro lugar (cfr. Díaz Hormigo, 2006a), son diversos, desde nuestro punto de vista, los 
figurado o traslaticio, sea éste metafórico, metonímico o relativo a algún tropo semejante, ya que tales palabras resultan transparentes por la conexión que existe entre los dos significados, el literal y el traslaticio (por ejemplo, en francés mouche con el significado de 'lunar postizo' está motivada por la analogía entre la forma del insecto y la del pequeño trozo de tafetán negro que las damas se colocan en el rostro para simular un lunar, así como en inglés están motivadas las palabras crane 'grúa, máquina para mover pesos pesados', tongue 'lengua, idioma' y bureau 'agencia, oficina', ya que cuando manifiestan esos significados están siendo empleadas figuradamente). Ahora bien, frente a la motivación fonética, que, al implicar la creación de palabras totalmente nuevas y, sobre todo, por poder explicar y justificar en base a sí misma la razón de ser de la constitución y de los constituyentes de tales palabras, puede ser considerada una motivación absoluta, las motivaciones morfológica y semántica, que también son llamadas por este autor (cfr. Ullmann, 1963[1951]: 36) motivación gramatical y motivación por el significado, respectivamente, figuran englobadas (cfr. Ullmann, 1974[1952]: 155-156; ${ }^{2} 1976[1962]$ : 105; 1977[1964]: 49-50), por los rasgos comunes que presentan entre sí y que las diferencian de la expresividad fónica, bajo las denominaciones de motivación etimológica -puesto que se explica la palabra por otros elementos del léxico y, por tanto, basándose en la 'etimología' entendida, no en la acepción correspondiente a la etimología histórica, sino en la que define a la etimología sincrónica o estática, esto es, en la de «sentimiento etimológico de los hablantes» (Ullmann, 1974[1952]: 155) ${ }^{23}-\mathrm{y}$, retomando,

aspectos que, referidos a la concepción de las formaciones derivadas como morfológicamente motivadas, deben ser puntualizados y/o modificados. Así, por una parte, debe quedar claro que, de entre las que generalmente son consideradas formaciones derivadas existentes en una lengua, este tipo de motivación puede radicar sólo en la estructura morfológica de aquellas palabras que están formadas por la adición, supresión o intercambio de afijos a elementos léxicos existentes en esa misma lengua, y no en la estructura morfológica de las consideradas también formaciones derivadas pero recibidas una vez formadas ya en otras lenguas sin evolución del vocablo primitivo (excursión, devoción) ni en la de las formaciones derivadas formadas en una lengua a partir de elementos léxicos pertenecientes a otros sistemas lingüísticos (populacho se ha formado a partir del vocablo latino populus). Pero, además, dichas formaciones complejas están motivadas morfológicamente sólo en las acepciones en las que su significado potencial o virtual coincida con su significado actual o de inventario, pero no en aquellas otras que, desde el punto de vista del significado, ya no están relacionadas, de modo total, con ninguna acepción de la palabra a partir de la cual tales derivados fueron formados (invitación, consumición, carga, poda están motivadas en la acepción en la que presentan el significado de 'acción' pero no en las otras acepciones en las que presentan significados más concretos). Asimismo, la formación derivada puede perder transparencia si la palabra primitiva o base de la formación ha desarrollado otras acepciones distintas y no conserva ya el significado que dio origen a la formación del derivado (fr. débonnaire 'bondadoso, complaciente' procede del sintagma de bonne aire 'de buena cepa', pero sólo el conocedor de la historia de la lengua francesa apreciará su conexión con aire 'nido de ave de rapiña', ya que para el hablante esa formación es totalmente opaca).

23 En efecto, Ullmann (1959: 327-328) postula la existencia de dos tipos de etimología: la etimología histórica, que tiene como objeto el estudio de la genealogía de las palabras, y la etimología sincrónica, que puede también ser llamada, siguiendo la denominación de J. Vendryes (1953. «Pour une étymologie statique», Bulletin de la Société de Linguistique de Paris XLIX, 1-19), quien se encargó asimismo de definirla y de establecer sus principios y tareas, etimología estática, la cual ha de ocuparse de la indagación de la red de asociaciones formales y semánticas que contraen unas palabras con otras en un sistema lingüístico determinado. En coherencia con tales postulados, U11mann ( ${ }^{2} 1976$ [1962]: 35-36) defiende que la investigación etimológica no debe consistir sólo en el estudio del origen, étimo o raíz de las palabras, sino que, por el contrario, ha de atenderse a una concepción más amplia de la etimología que, frente a los métodos anteriores, por una parte, no se limita sólo al estudio del origen de la palabra, sino que pretende indagar la historia completa de la palabra, y, por otra, no trata las palabras aisladamente, sino como partes de grupos más amplios. De este modo, Ullmann parece manifestarse de acuerdo con lo establecido anteriormente por 
tal como el mismo Ullmann indica, el nombre empleado ya por Saussure, quien, sin embargo, como ha sido visto y Ullmann señala, sólo la refirió a los compuestos y derivados y no a las expresiones figuradas del lenguaje, la de motivación relativa -puesto que, en realidad, llegado un momento, los componentes que resultan del análisis último de estas palabras no pueden ser ni explicados ni justificados, ya que no son ya motivados sino, por el contrario, arbitrarios u opacos-.

5.3.2. Parece distinta, al menos en principio, la concepción de la teoría de la motivación de P. Guiraud ( ${ }^{9} 1969$ [1955]: 25-26), pues este autor delimita cuatro tipos: la motivación fonética - directa y natural, la motivación metasémica, la motivación morfológica y la motivación paronímica, correspondiendo los dos primeros a motivaciones externas y los otros dos a motivaciones internas. En efecto, la motivación externa está basada en la relación entre la cosa significada y la forma significante, asociación que surge del exterior del sistema de la lengua y que puede adoptar los tipos de 1) una motivación fonética - directa y natural en las onomatopeyas (cfr. 4.1.) y 2) una motivación metasémica en los cambios de sentido (la designación de un pez con el significante francés loup). Por su parte, se engloban en la motivación interna aquellos tipos que tienen su origen en el interior del sistema de la lengua: 1) la motivación morfológica, que es la de las palabras derivadas y compuestas (fr. bananier, derivado de banane), y 2) la motivación paronímica, basada en la asimilación o confusión entre formas idénticas (homónimas) o análogas (parónimas) (el sentido del sintagma francés jour ouvrable está influenciado por el del verbo ouvrir).

Pero contradice a esta clasificación de la motivación la que expone Guiraud en el apartado VI de ese mismo capítulo de su obra (Guiraud, ${ }^{9} 1969$ [1955]: 28-29), pues ahora señala que la motivación que en su origen presenta toda palabra puede estar basada o bien en la relación natural entre la forma acústica y la cosa significada (caso de las onomatopeyas y las exclamaciones, que antes, no obstante, no había mencionado) o en la relación intralingüística de las palabras en el interior de la lengua, que puede ser morfológica (derivación, composición) o semántica (cambios de sentido).

En este sentido, más semejante a esta última, y también a la presentada antes por Ullmann (cfr. 5.3.1.), es la teoría de la motivación lingüística expuesta en la edición en español de la monografía La sémantique de Guiraud, ya que, según figura en esta traducción, el autor francés (1981[1960]: 21-22) distingue, además de la motivación natural, característica de las

\footnotetext{
Wartburg ('1991[1946]: 188-200), quien declara explícitamente que la etimología se debe ocupar de observar, describir y explicar los cambios que experimenta una palabra a lo largo de la historia. Por tanto, no basta con investigar sólo el origen de una palabra o de un grupo de palabras, «la tenue línea que une entre sí el origen y término de una evolución» (Wartburg ${ }^{2}$ 1991[1946]: 199), sino que tiene que seguir al grupo estudiado y ocuparse de las vicisitudes por las que ha atravesado una determinada palabra o un grupo de palabras que comparten una misma raíz y seguir la trayectoria del grupo en cuestión a lo largo de la historia de la lengua, observando todas sus ramificaciones y sus relaciones con otros grupos de palabras durante todo el tiempo que pertenece a la lengua. Y resulta obvio que en esta indagación acerca de los orígenes, vicisitudes y ramificaciones de las palabras y de grupos de palabras a lo largo de la historia se ha de prestar atención, con particular insistencia, al capítulo de la motivación y de los cambios o variaciones en la motivación, sean éstas debidas a la pérdida de la motivación de las palabras por el propio desarrollo evolutivo de la lengua o, por el contrario, a la adquisición de la motivación de palabras que eran o se habían vuelto opacas y se hacen transparentes en el curso de la historia. En este sentido, la teoría de la motivación de las palabras es uno de los temas en el que, como bien señala Ullmann (1959, esp. págs. 325, 331; 1977[1964]: 35), con mayor claridad se observan las relaciones que existen entre semántica y etimología, así como uno de los puntos en los que la investigación etimológica se puede servir con mayor provecho de los avances de la semántica.
} 
onomatopeyas (cfr. 4.1.), la denominada motivación endoglótica (intralingüistica), que no consiste, como en el caso de la motivación natural, en una asociación o nexo entre la forma acústica de la palabra y la cosa significada, sino que atañe a asociaciones constatables entre las diferentes palabras en el interior de la lengua - de ahí su denominación y que sea acentuado su carácter intralingüístico-- Sin embargo, a pesar de identificar esta motivación con la que Saussure llama relativa, el autor francés establece una distinción en el ámbito de la misma entre dos tipos, pues considera que dicha motivación endoglótica puede ser morfológica, la característica de la derivación y la composición (así, manzano, que deriva de manzana, e imposible, de posible, son palabras motivadas morfológicamente), o semántica, propia de los cambios de sentido, en los que una realidad es nombrada por el significante de otra con la que presenta caracteres comunes (por ejemplo, pluma (de escribir) resulta motivada semánticamente por la pluma del ave y hoja (de papel) encuentra su motivación en la hoja del árbol).

Pero, a pesar de tales distinciones, según Guiraud (1956: 281-283; ${ }^{9} 1969$ [1955]: 26-27; 1981[1960]: 22-23), todas las palabras están al menos etimológicamente motivadas -esto es, se encuentran motivadas en su origen o, lo que viene a ser lo mismo, en el momento de su formación/creación ${ }^{24}$-, y esta motivación puede surgir del interior del sistema de la lengua (lo que apunta que se observa, fundamentalmente, en las formaciones compuestas y derivadas); del exterior del sistema de la lengua (como, según indica, sucede con los préstamos, que son motivados en sus lenguas originales, y con los cambios de sentido), o desde el interior y el exterior al mismo tiempo ${ }^{25}$.

24 En este sentido, siguiendo la misma concepción de Wartburg ( ${ }^{2} 1991$ [1946]: 188-200), que, como ha sido visto (cfr. n. 23), es compartida también por Ullmann, establece Guiraud (1956: 281-283; 1966, esp. pág. 145), que es tarea de la etimología desentrañar y explicar el contexto histórico y el contexto lingüístico de cada palabra. Por ello, a pesar de que tradicionalmente la etimología se ha entendido como una ciencia histórica, excluyendo todo lo concerniente a motivaciones internas y todo lo relativo a los mecanismos y procesos de creación léxica, le corresponde proceder a la datación de las palabras, su localización geográfica y social, la historia del significado, la evolución fonética del significante, etc., si bien, a lo largo del proceso, se pueden determinar muchas etimologías dudosas, oscuras o no satisfactorias, que, según señala Guiraud, podrían esclarecerse cuando se conozca la historia de la palabra, pero, en el caso de que sea una palabra rebelde al análisis histórico, se puede extraer su motivación del sistema, pues ésta se puede averiguar analizando el campo morfosemántico en el que está integrada. De este modo, una palabra habrá de ser confrontada con todos los vocablos susceptibles de mantener con ella relaciones o de forma o de sentido y se descubrirá su motivación. Una aplicación práctica de los asertos teóricos expuestos en su artículo de 1956 es llevada a cabo por P. Guiraud en su trabajo de 1966, en el que procede a la configuración y análisis del campo morfosemántico de los nombres que designan al gato en francés. Estos modelos de análisis y estudio del léxico, que se encuentran a caballo entre la morfología y la semántica y que han tenido posteriormente diversas aplicaciones lingüísticas, destacando en este sentido su utilidad, desde una perspectiva histórica, para la reconstrucción etimológica, su adaptación a la lexicología dialectal y la perfecta sistematización que ofrecen a distintos fenómenos léxicos como la jerga, el eufemismo o el disfemismo, se encuentran en la base del surgimiento, en la década de los 60, de una nueva disciplina o ciencia lingüística, denominada morfosemántica, que fue creada con el propósito de estudiar específicamente las conexiones existentes entre la morfología y la semántica con la etimología, fundamentalmente, la motivación, remotivación, inmotivación, retromotivación y pérdida de la motivación de las palabras, aunque también determinados aspectos relativos al simbolismo fónico y a la fonoestilística, ya que cualquier aspecto que tenga que ver con la forma y el significado es considerado morfosemántico.

25 No obstante, para P. Guiraud ha de tenerse en cuenta que dicha motivación, por una parte, no está determinada, ya que la creación de palabras no está sometida a reglas en lo que se refiere a la fuente o tipo de motivación en la que ha de basarse, por lo que cualquier motivación es posible (así, el cucú recibe su nombre por onomatopeya, el (pájaro) carpintero por metáfora y el petirrojo por sinécdoque; el encargado de vender las especias en Francia es el épicier, que es derivado de épice, pero el que vende el tabaco es el marchand de tabac y las medicinas el pharmaceutique y 
5.3.3. Asimismo, Baldinger (1970) reconoce, además de una motivación primaria o directa -esto es, dada a través de la realidad-a la que se ajustan las palabras onomatopéyicas (cfr. 4.1.), la que denomina motivación indirecta o secundaria, que no define sino que sólo ejemplifica con el verbo encabritarse «empinarse el caballo [como un cabrito], afirmándose sobre los pies y levantando las manos», que no está motivado de modo directo (a través de la realidad), sino de modo indirecto o secundario a través de cabra, y de la que dice que en ella se puede incluir al menos todo el metaforismo, aunque, según afirma, puesto que todos los matices de significación están basados en los precedentes, se podría considerar que toda la semántica está basada en motivaciones secundarias. Pero este autor no hace referencia a la teoría de la motivación relativa de Saussure y tampoco a si los derivados y compuestos responden o no a la que él denomina motivación indirecta o secundaria.

6. De lo expuesto en los apartados anteriores se desprenden una serie de conclusiones, que intentaremos sintetizar en lo que sigue.

6.1. En efecto, por una parte, se ha mostrado que la noción saussureana de motivación lingüística, en tanto que en el $C L G$ se presenta identificada con la de arbitrariedad relativa o de limitación de lo arbitrario, no puede ser entendida sin examinar previamente el principio de la arbitrariedad del signo lingüístico, el cual, a pesar de que, como señala Coseriu (1986[1973]: 27), «es constante en la teoría del lenguaje, como noción, desde Aristóteles, y como término, por lo menos desde J. C. Escalígero», se atribuye generalmente a F. de Saussure, tal vez por la tantas veces denunciada, especialmente por el propio lingüista rumano (cfr. Coseriu, 1986[1973], esp. págs. 15-16 y los distintos estudios recopilados en Coseriu, 1977), conocida fractura producida entre la lingüística actual y sus propias tradiciones. Asimismo, para demostrar el tan proclamado en el $C L G$ carácter radicalmente arbitrario del signo lingüístico, Saussure recurre de nuevo a la tradición y a sus propios coetáneos, pues en ellos se encuentra la expresión de una serie de ideas que le sirven ahora al lingüista suizo como argumentos para demostrar la inexistencia de vínculo entre significante y significado, en concreto, las que giran en torno a la diversidad de lenguas; la inmutabilidad, desde el punto de vista sincrónico, del lazo significante-significado, y la mutabilidad, desde el punto de vista diacrónico, de esta relación, pruebas estas que, no obstante, el maestro ginebrino reelabora, dándoles, en parte, una nueva interpretación, en el marco de una teoría coherente, y a las que añade la de la relatividad y diferencialidad de los valores de los signos lingüísticos, que formula a partir del concepto de «valor lingüístico» elaborado por él mismo, por lo que dicha consecuencia de la ausencia de vínculo entre significante y significado sí puede ser considerada una aportación original del considerado precursor del estructuralismo lingüístico a la lingüística posterior. Pero hasta tal punto opta Saussure por insistir en la naturaleza arbitraria del signo lingüístico que, valiéndose también ahora de razones emitidas antes por otros con el mismo propósito, llega a despreciar el papel que desempeñan en las lenguas las onomatopeyas, disgregándose así de la concepción de muchos pensadores anteriores, coetáneos y posteriores a él mismo, entre los cuales se incluyen incluso discípulos suyos integrantes de la denominada escuela

estas palabras no son derivadas), y, por otra, no es determinante ni necesaria, de tal modo que la motivación de las palabras, cuya actualización radica también en una asociación convencional, puede oscurecerse y hasta borrarse (ya no se perciben las asociaciones etimológicas entre el frailecillo (pájaro) y el fraile, el banco (financiero) y el banco para sentarse, sandwich y Lord Sandwich, los espejuelos y el espejo), con los posibles cambios o alteraciones de sentido que dichas pérdidas de motivación pueden implicar. 
preestructuralista de Ginebra, que defienden la existencia de una relación natural o directa entre la forma o estructura fonética de la palabra expresiva y la realidad que ésta simboliza, paralelismo que, con el tiempo, condujo a determinados semantistas a postular un tipo de motivación lingüística de carácter fonético, propio de las onomatopeyas, el cual en la actualidad es plenamente reconocido y figura entre los habitualmente enumerados. En cualquier caso, pese a la generalidad de la postura moderna de que cada lengua contiene palabras arbitrarias u opacas y otras que son motivadas o transparentes, al menos dos de las razones citadas por el lingüista suizo para hacer valer el carácter convencional o arbitrario de los signos lingüísticos -en concreto, las referidas a la diversidad espacial y temporal de las lenguas-, son, junto a la idea de la existencia de palabras 'sinónimas', cuasisinónimas y homónimas o polisémicas en las lenguas, pruebas comúnmente citadas por estos autores, aunque sin mencionar ni al maestro de Ginebra ni a ninguna de sus fuentes o predecesores, para defender también la no existencia de lazo entre el significante y el significado del signo lingüístico.

6.2. Ahora bien, la delimitación saussureana entre signos radicalmente arbitrarios y signos que sólo lo son relativamente incluye, aunque sin llegar a suprimirlo, una importante restricción al principio de la arbitrariedad del signo lingüístico tal como éste aparece formulado en el $C L G$, si bien, a la vez, puede ser considerada como la lógica consecuencia de este principio visto desde una perspectiva exclusivamente sincrónica. En efecto, está claro, como bien señala Godel (1974-75: 78-79) a partir de lo expresado por el lingüista suizo, que ni la definición de signo lingüístico propuesta ni la mención de sus dos caracteres fundamentales -la arbitrariedad del signo y la linealidad del significante- contribuyen a definir qué es lo que hace de la lengua un sistema. Para subsanar esta deficiencia, Saussure introduce la noción de motivación relativa o de limitación de lo arbitrario, la cual pone en juego dos tipos de relaciones: una, la que ya había sido tenida en cuenta para formular la definición de signo lingüístico, esto es, la relación que se establece en el interior del signo en la asociación entre el significante y el significado, la cual implica considerar a los signos aisladamente, y otra, la que atiende a las asociaciones entre signos, en concreto, a las relaciones sintagmáticas y asociativas que contrae un signo con otro $u$ otros signos de la lengua. Y aunque no aparece en el $C L G$ ninguna definición explícita de arbitrariedad relativa, a partir de las observaciones y ejemplos propuestos por el propio Saussure, se infiere que la noción de motivación relativa o de limitación de lo arbitrario - puesto que implica, como hemos visto, la existencia de relaciones sintagmáticas y asociativas entre los signos y éstos, en otra parte, habían sido identificados con las palabras- no concierne más que a aquellos signos analizables (sintagmas) que son palabras derivadas y compuestas ${ }^{26}$. Podemos, no obstante, siguiendo a Zawadowski (1958),

26 No obstante, Godel (1974-75: 86-87) se cuestiona si esta idea de que la limitación de lo arbitrario no concierne más que a las palabras derivadas y compuestas responde realmente a la concepción de Saussure, esto es, si no se trata más bien de una simplificación, por parte del propio lingüista ginebrino, de su propia teoría para exponer y ejemplificar con mayor claridad y didactismo a sus estudiantes la sustancial modificación introducida en el principio del carácter arbitrario del signo lingüístico. Estas dudas le surgen a Godel, fundamentalmente, tras examinar una nota personal de Saussure, al parecer destinada a las lecciones de mayo de 1911 pero que, sin embargo, sólo fue utilizada en parte, en la que aparecen citados distintos ejemplos que prueban que el lingüista suizo consideró otros modos de limitación más que los procedimientos morfológicos de la composición y de la derivación. Además, según Godel, hay otros testimonios más antiguos que mostrarían que la concepción de Saussure no es como se ha visto. En efecto, en el $1^{\circ}$ curso, sobre el Umlaut de los plurales alemanes, Saussure sostiene que la formación analógica no implica siempre un análisis positivo (segmental) y, en otro lugar, se había preguntado también, sin pronunciarse, si podía 
puntualizar más exactamente, desde un punto de vista teórico, esta noción de motivación relativa y, en este sentido, postular que para el lingüista suizo están relativamente motivadas sólo aquellas palabras cuyos elementos constitutivos contraen una relación sintagmática entre sí y una relación asociativa con aquellos otros elementos de la lengua con los que tienen una vinculación al mismo tiempo de índole formal y semántica; por tanto, los compuestos y derivados. Lo que sí debe quedar claro es que no hay motivación en el interior del signo -la relación significante-significado es arbitraria-, sino que es el entorno sintagmático y asociativo del signo, en el sentido antes precisado, el que produce la limitación de lo arbitrario, fenómeno este que, obviamente, tampoco se hace patente si se examina al signo haciendo abstracción del sistema.

6.2.1. El que la noción de lo arbitrario relativo se fundamente en las relaciones que contraen signos lingüísticos que coexisten en sincronía explica que Saussure no reconozca la existencia de una motivación fónica, característica de las onomatopeyas y las exclamaciones, pues esta motivación implicaría una limitación de lo arbitrario del significante del signo en su relación con la realidad exterior y no en su relación con otros signos del sistema de la lengua. De ahí también que la motivación fónica no pueda ser considerada una motivación intralingüística, frente a la motivación relativa, que, puesto que no puede venir dada desde fuera del sistema de la lengua sino sólo por y dentro de éste, sí puede ser denominada así.

6.3. Para la formulación de la moderna teoría de la motivación lingüística, se han tenido en cuenta tanto las observaciones emitidas por Saussure en torno a la motivación relativa como su propia interpretación de las formaciones derivadas y compuestas como relativamente motivadas, la cual, por otra parte, como hemos indicado, no parece del todo original de Saussure sino que ya figura en la Gramática da linguagem portuguesa de F. de Oliveira, en quien influyó Varrón, y después del gramático portugués, al menos, en la Philosophia prima de C. Wolff. Ahora bien, frente al único tipo de motivación relativa reconocido por el lingüista suizo ${ }^{27}$, en la actualidad se delimitan, además de la motivación fónica, al menos, otras dos clases, la morfológica y la semántica ${ }^{28}$, las cuales figuran generalmente agrupadas

haber asociación por la función solamente, por ejemplo, entre las diversas formas de un mismo caso (latín regibus, lupis).

27 Por tanto, es este tipo de motivación el único en que pensaba Saussure ( $\left.{ }^{21} 1981[1916]: 221-222,268\right)$ tanto cuando esbozó la clasificación de las lenguas en los dos tipos de lexicológicas y gramaticales como cuando hizo referencia a la variabilidad en la proporción de elementos arbitrarios y motivados que se observa en el interior del léxico si se comparan distintos estadios de una misma lengua o un mismo período en lenguas distintas, siendo, además, el análisis de la estructura morfológica del vocabulario el que ofrece los datos más objetivos para realizar estudios comparativos interlingüísticos e intralingüísticos de este tipo, aspectos estos que, como hemos apuntado en la n. 18, aunque apenas fueron esbozados por Saussure, han sido ampliamente desarrollados por Ullmann.

28 En efecto, estos tres tipos de motivación lingüística citados -la motivación fonética, la motivación morfológica y la motivación semántica- son los más habitualmente reconocidos y los que figuran citados por la mayoría de los autores, presentándose, por tanto, en este sentido como particularmente novedosa la clasificación de los diferentes fenómenos de motivación lingüística propuesta por Casas Gómez (1996: 46-47; 2002: 106 n. 113), pues en ella aparecen distinguidas, en principio, cuatro clases distintas de motivación, si bien la segunda de las señaladas abarca dos de los tres tipos anteriormente enumerados. En concreto, diferencia el autor citado: 1) la motivación primaria, natural o directa de tipo fonético, característica de las onomatopeyas; 2) las motivaciones secundarias o indirectas de carácter intralingüístico, en las que distingue a) por una parte, las motivaciones morfológicas, propias de los mecanismos de formación de palabras en sentido estricto - por tanto, de los procedimientos de la derivación, la denominada composición léxica, gráfica, ortográfica, perfecta o estricta y la parasíntesis-, y b) por otra, las motivaciones semánticas, relacionadas con los factores que originan los denominados cambios de sentido o cambios semánticos; 3 ) 
bajo las denominaciones de motivación etimológica, relativa, endoglótica, intralingüística, indirecta o secundaria, a pesar de que es sólo la motivación morfológica la que se identifica con la motivación relativa tal como la concibió y formuló Saussure, quien no se refiere a la motivación de las expresiones figuradas del lenguaje tal vez porque se percató de que ésta, aunque presenta algunos caracteres en común con la de las palabras derivadas y compuestas, realmente no funciona del mismo modo ${ }^{29}$, por lo que, al igual que la motivación fónica, queda fuera de la noción de motivación lingüística que figura expuesta en el CLG.

\section{Referencias bibliográficas}

Alonso, A. $\left({ }^{21} 1981[1945]\right):$ «Prólogo a la edición española». En Saussure, F. de, págs. 7-30.

Arens, H. (21975[1969]): La Lingüistica. Sus textos y su evolución desde la Antigüedad hasta nuestros dias. Madrid, Gredos, 2 ts.

Baldinger, K. (1970): «Significante y realidad». En Baldinger, K.: Teoría semántica. Hacia una semántica moderna. Madrid, Alcalá, págs. 29-33.

Bally, Ch. ( ${ }^{4} 1965$ [1932]): Linguistique générale et lingüistique française. Bern, A. Francke AG Verlag. Benveniste, É. (21972[1939]): «Naturaleza del signo lingüístico». En Benveniste, É.: Problemas de lingüistica general. México, Siglo XXI, págs. 49-55.

Bolinger, D. L. (1949): «The sign is not arbitrary», Boletín del Instituto Caro y Cuervo, V, págs. 52-62.

la motivación terminológica de carácter interlingüístico, referida al lenguaje técnico-científico, pues, desde el punto de vista del significante, sus términos se identifican con el objeto creado, y 4) la motivación por tabú lingüístico de carácter extralingüístico, que, al igual que la anterior, se basa en la relación directa entre el significante de la palabra y la realidad designada, pero, en este caso, el origen de dicha conexión se explica a partir de una concepción mágica, característica de sociedades primitivas, que lleva a atribuir a las palabras un poder intrínseco. Para el desarrollo de esta clasificación de cuatro clases diferentes de motivación lingüística propuesta por M. Casas Gómez, cfr. García Manga (2002) y para los problemas que, desde nuestro punto de vista, plantea la asunción de las dos últimas clases de motivación señaladas por Casas Gómez, cfr. Penadés Martínez y Díaz Hormigo (2008, esp. n. 10).

29 En efecto, mientras que en la motivación morfológica se cumplen los dos principios establecidos por Saussure para la que él denomina motivación relativa - esto es, una relación sintagmática entre los elementos constitutivos de las palabras motivadas y una relación asociativa de cada uno de estos elementos con otros signos del sistema con los que presentan una vinculación formal y semántica-, en la motivación semántica sólo se observa la relación 'asociativa' entre un signo con otro signo con el que coincide desde el punto de vista del significante y que designa en la realidad un objeto o concepto con el que lo designado por el primero presenta o una relación de analogía o semejanza, o una relación de contigüidad espacial o temporal, o alguna otra relación de carácter extralingüístico. En definitiva, la motivación semántica está basada en asociaciones entre signos que designan a objetos o conceptos que están relacionados de alguna manera en la realidad. De ahí que, tradicionalmente, las creaciones metafóricas y las metonímicas y sinecdóquicas, que son las que precisamente responden a la denominada motivación semántica, hayan sido definidas como creaciones por analogía o semejanza (el hablante para designar un objeto toma el nombre de otro con el que aquél presenta cierta similitud o semejanza) o como creaciones por contigüidad espacial o temporal (el hablante para designar un objeto toma el nombre de otro que se halla en una relación de contigüidad espacial o temporal con el objeto designado por el primero). En este sentido, consideramos que, si bien la motivación semántica, frente a la motivación fonológica y al igual que la motivación morfológica, puede ser explicada a través de relaciones existentes entre signos de un mismo sistema lingüístico, en el establecimiento de tales relaciones entre signos interviene, al igual que se observa en la motivación fonológica y a diferencia de lo que sucede en la motivación morfológica, un condicionamiento externo o componente extralingüístico que contribuye a explicar la transparencia de tales formaciones motivadas semánticamente. Para el desarrollo de las ideas expuestas en esta nota, cfr. Penadés Martínez y Díaz Hormigo (2008). 
Casas Gómez, M. (1996): «El poder mágico de la palabra», Trivium. Anuario de Estudios Humanísticos, 8. In memoriam Prof. José Luis Millán Chivite, págs. 29-52.

Casas Gómez, M. (2002): Los niveles del significar (= Documentos de Investigación Lingüistica, 7). Cádiz, Servicio de Publicaciones de la Univ. de Cádiz.

Coseriu, E. (1977): Tradición y novedad en la ciencia del lenguaje. Estudios de historia de la lingüistica. Madrid, Gredos.

Coseriu, E. (1977[1967]): «L'arbitraire du signe. Sobre la historia tardía de un concepto aristotélico». En Coseriu, E. (1977), págs. 13-61.

Coseriu, E. ( $\left.{ }^{3} 1978[1973]\right)$ : Sincronía, diacronía e historia. El problema del cambio lingüistico. Madrid, Gredos.

Coseriu, E. (1986[1973]): «Premisas históricas de la lingüística moderna». En Coseriu, E.: Lecciones de lingüística general. Madrid, Gredos, 1a reimpr., págs. 15-32.

Díaz Hormigo, M. T. (2003a): Morfología. Cádiz, Servicio de Publicaciones de la Univ. de Cádiz.

Díaz Hormigo, M. T. (2003b): «Delimitación terminológica y conceptual de las unidades lingüísticas del nivel sintáctico-semántico suboracional», Estudios de Lingüistica de la Universidad de Alicante, 17 , págs. $247-262$.

Díaz Hormigo, M. T. (2006a): «Arbitrariedad, motivación morfológica y variación lingüística». En Luque Durán, J. de Dios (ed.): Actas del V Congreso Andaluz de Lingüística General. Homenaje al profesor José Andrés de Molina Redondo. Tomo segundo. Granada, Granada Lingvistica y Método Ediciones, págs. 747-761.

Díaz Hormigo, M. T. (2006b): «Releyendo a Saussure. Consideraciones en torno a la denominada teoría de la motivación lingüística». En Roldán Pérez, A., Escavy Zamora, R., Hernández Sánchez, E., Hernández Terrés, J. M. y M. I. López Martínez (eds.): Caminos actuales de la Historiografía Lingüística. Actas del V Congreso Internacional de la Sociedad Española de Historiografía Lingüistica. Tomo I. Murcia, Univ. de Murcia, págs. 431-443.

Engler, R. (1962): «Théorie et critique d'un principe saussurien: l'arbitraire du signe», Cahiers Ferdinand de Saussure, 19, págs. 5-66.

Engler, R. (1964): «Compléments a l'arbitraire», Cahiers Ferdinand de Saussure, 21, págs. 25-32.

Frei, H. (1974): «Le mythe de l'arbitraire absolu». En Studi saussuriani per Robert Godel a cura di René Amacker, Tullio De Mauro, Luis J. Prieto. Bologna, Il Mulino, págs. 121-131.

García, C. (1960): Contribución a la historia de los conceptos gramaticales. La aportación del Brocense. Madrid, C.S.I.C.

García Manga, M. C. (2002): «La motivación lingüística: propuesta de clasificación», Res Diachronicae. Anuario de la Asociación de los Jóvenes Investigadores de Historiografía e Historia de la Lengua Española, 1, págs. 159-168.

Godel, R. (1957): Les sources manuscrites du Cours de linguistique générale de F. de Saussure. Genève y Paris, E. Droz-Minard.

Godel, R. (1973): «Reseña de Koerner (1972b)», Cahiers Ferdinand de Saussure, 28, págs. 59-62.

Godel, R. (1974-75): «Problèmes de linguistique saussurienne», Cahiers Ferdinand de Saussure, 29, págs. 79-89.

Guiraud, P. (1956): «Les champs morpho-sémantiques. (Critères externes et critères internes en étymologie)», Bulletin de la Société de Lingüistique de Paris, 52:1, págs. 265-288.

Guiraud, P. (1966): «Le champ morpho-sémantique des noms du chat», Bulletin de la Société de Lingüistique de Paris, 61:1, págs. 128-145.

Guiraud, P. ( ${ }^{9} 1969$ [1955]): La sémantique. Paris, Presses Universitaires de France.

Guiraud, P. (1981[1960]): La semántica. México y Madrid, Fondo de Cultura Económica, 5a reimpr.

Koerner, E. F. K. (1972a): Bibliographia Saussureana, 1870-1970. An annotated, classified bibliography on the background, development and actual relevance of Ferdinand de Saussure's general theory of language. Metuchen (N.J.), Scarecrow Press. 
Koerner, E. F. K. (1972b): Contribution au débat post-saussurien sur le signe linguistique. Introduction générale et bibliographie annotée. The Hague y Paris, Mouton.

Koerner, K. (1989[1987]): «On the problem of 'influence' in linguistic historiography». En Koerner, K.: Practicing linguistic historiography (= Studies in the history of the language sciences, 50), Amsterdam y Philadelphia, John Benjamins, págs. 31-46.

Lázaro Carreter, F. ( ${ }^{3} 1987$ [1953]): Diccionario de términos filológicos. Madrid, Gredos, 7a reimpr.

Lyons, J. (1977[1968]): Introduction to theoretical linguistics, Cambridge, London, New York y Melbourne, Cambridge Univ. Press, 7a reimpr.

Lyons, J. (1980[1977]): Semántica. Barcelona, Teide. Versión castellana: R. Cerdà

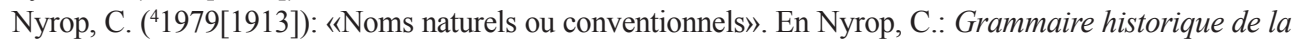
langue française (Honorée du priz diez et du prix saintour), IV. Sémantique. Genève, Slatkine Reprints, págs. 396-402.

Oliveira, F. de (1981[1536]): Gramática da linguagem portuguesa. Edição fac-similada. Lisboa, Biblioteca Nacional, Ministério da Cultura e Coordenação Científica, Secretaria de Estado da Cultura.

Penadés Martínez, I. (2006): «La motivación lingüística y la motivación fraseológica». En: VII Congrés de Lingüística General, Barcelona. Barcelona, Univ. de Barcelona.

Penadés Martínez, I. y Díaz Hormigo, M. T. (2008): «Hacia la noción lingüística de motivación». En Álvarez de la Granja, M. (ed.): Lenguaje figurado y motivación. Una perspectiva desde la fraseología. Frankfurt am Main, Peter Lang, págs. 51-68.

Robins, R. H. (1974[1967]): Breve historia de la lingüistica. Madrid, Paraninfo.

Saussure, F. de ( $\left.{ }^{21} 1981[1916]\right):$ Curso de lingüistica general. Publicado por Ch. Bally y A. Sechehaye con la colaboración de A. Riedlinger. Buenos Aires, Losada.

Saussure, F. de (2004[2002]): Escritos sobre lingüistica general. Barcelona, Gedisa.

Ullmann, S. (1949): «Word-form and word-meaning», Archivum linguisticum, I, págs. 126-139.

Ullmann, S. (1959): «Sémantique et étymologie», Cahiers de l'Association Internationale des Études Françaises, XI, págs. 323-335.

Ullmann, S. (1963[1951]): Words and their use. London, Frederick Muller Ltd., reimpr.

Ullmann, S. (1974[1952]): Introducción a la semántica francesa. Madrid, CSIC., reimpr.

Ullmann, S. (21976[1962]): Semántica. Introducción a la ciencia del significado. Madrid, Aguilar.

Ullmann, S. (1977[1964]): Lenguaje y estilo. Madrid, Aguilar, 2a reimpr.

Ullmann, S. (1979[1973]): Significado y estilo. Madrid, Aguilar.

Varrón, M. T. (1990): De lingua latina. Barcelona, Anthropos.

Wartburg, W. von (21991[1946]): Problemas y métodos de la lingüistica. Madrid, CSIC.

Zawadowski, L. (1958): «The so-called relative motivation in language». En: Omagiu lui Iorgu Iordan cu prilejul impliniri a 70 de ani. Bucureşti: Editura Academiei Republicii Populare Romîne, págs. 927-937. 